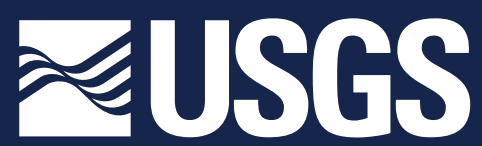

science for a changing world

Prepared in cooperation with the National Oceanic and Atmospheric Administration, FourBridges, European Space Agency, and European Association of Remote Sensing Companies

\title{
Demonstrating the Value of Earth Observations-Methods, Practical Applications, and Solutions-Group on Earth Observations Side Event Proceedings
}
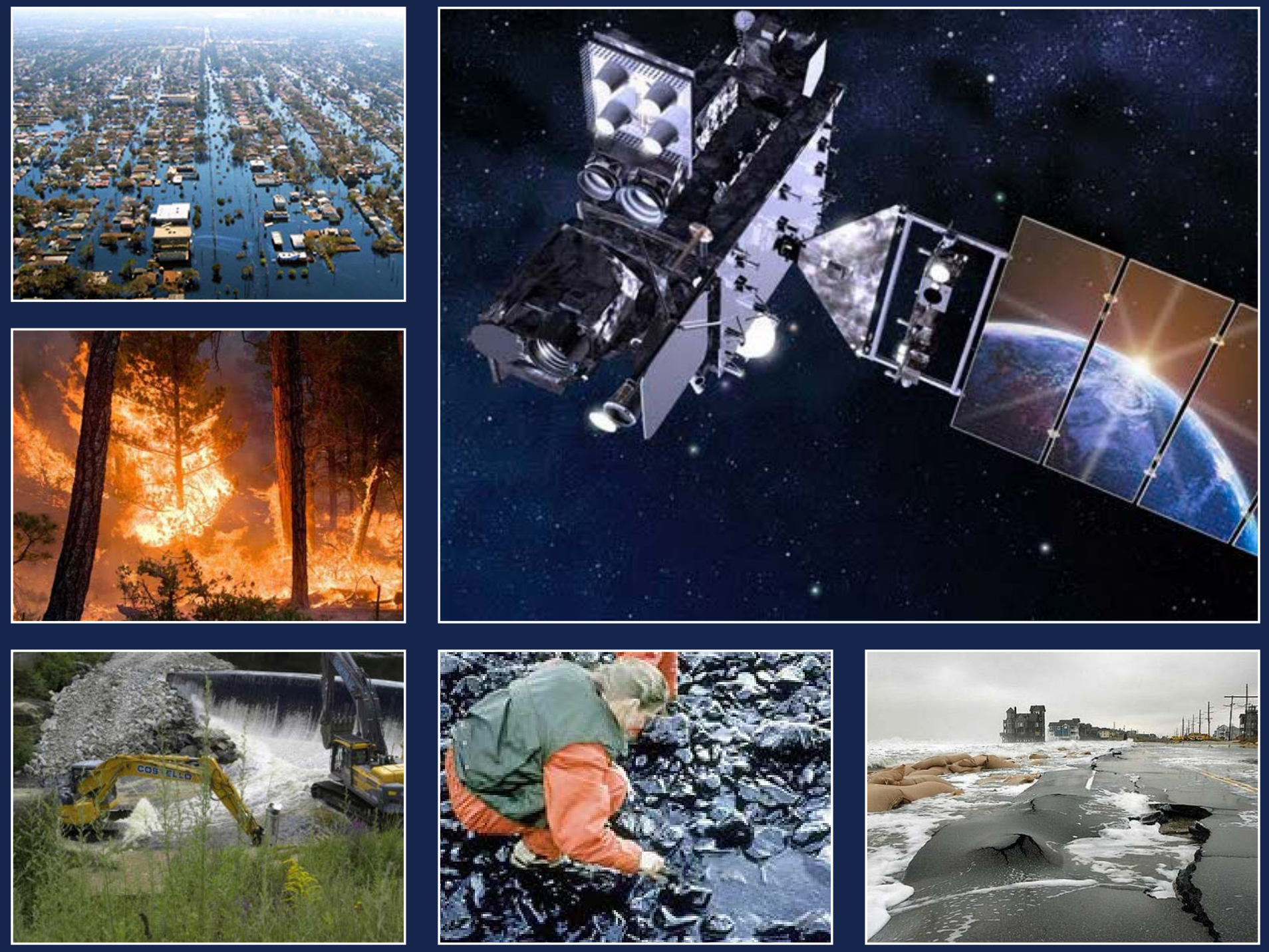

Open-File Report 2019-1033

U.S. Department of the Interior

U.S. Geological Survey 


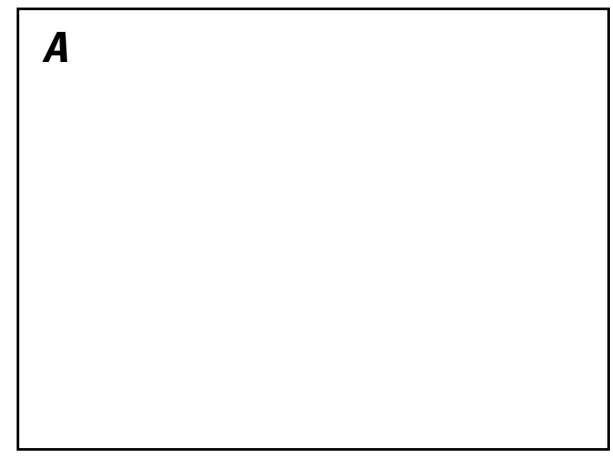

\section{D}

B

$\boldsymbol{E}$

$\boldsymbol{F}$

C

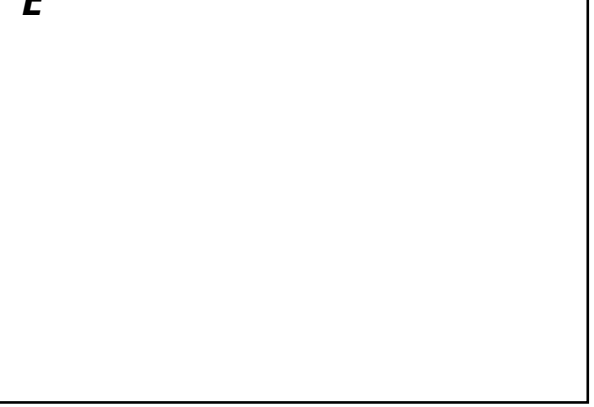

Cover. $A$, Urban flooding. $B$, Forest fire. $C$, Dam construction. $D$, Illustation of a satellite. $E$, Oil spill investigation. $F$, Coastal flooding. All images from the National Oceanic and Atmospheric Administration. 


\section{Demonstrating the Value of Earth Observations-Methods, Practical Applications, and Solutions-Group on Earth Observations Side Event Proceedings}

By Francoise Pearlman, Collin B. Lawrence, Emily J. Pindilli, Denna Geppi, Carl D. Shapiro, Monica Grasso, Jay Pearlman, Jeffery Adkins, Geoff Sawyer, and Alessandra Tassa

Prepared in cooperation with the National Oceanic and Atmospheric Administration, FourBridges, European Space Agency, and European Association of Remote Sensing Companies

Open-File Report 2019-1033 


\title{
U.S. Department of the Interior \\ DAVID BERNHARDT, Secretary
}

\author{
U.S. Geological Survey \\ James F. Reilly II, Director
}

U.S. Geological Survey, Reston, Virginia: 2019

For more information on the USGS - the Federal source for science about the Earth, its natural and living resources, natural hazards, and the environment-visit https://www.usgs.gov or call 1-888-ASK-USGS.

For an overview of USGS information products, including maps, imagery, and publications,

visit https://store.usgs.gov.

Any use of trade, firm, or product names is for descriptive purposes only and does not imply endorsement by the U.S. Government.

Although this information product, for the most part, is in the public domain, it also may contain copyrighted materials as noted in the text. Permission to reproduce copyrighted items must be secured from the copyright owner.

Suggested citation:

Pearlman, F., Lawrence, C.B., Pindilli, E.J., Geppi, D., Shapiro, C.D., Grasso, M., Pearlman, J., Adkins, J., Sawyer, G., and Tassa, A., 2019, Demonstrating the value of Earth observations-Methods, practical applications, and solutions-Group on Earth Observations side event proceedings: U.S. Geological Survey Open-File Report 2019-1033, 33 p., https://doi.org/10.3133/ofr20191033.

ISSN 2331-1258 (online) 


\section{Acknowledgments}

We would like to acknowledge the following organizations for their co-sponsorship of the workshop: the Group on Earth Observations, the National Oceanic and Atmospheric Administration, the European Association of Remote Sensing Companies, the European Space Agency, and FourBridges (nonprofit research organization). 



\section{Contents}

Acknowledgments ……....................................................................................................................

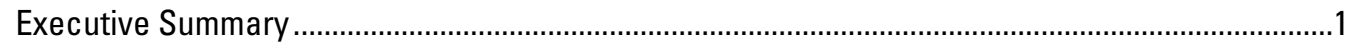

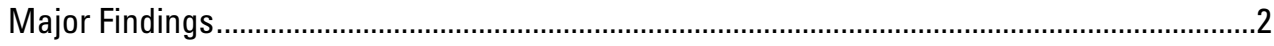

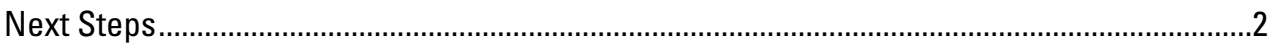

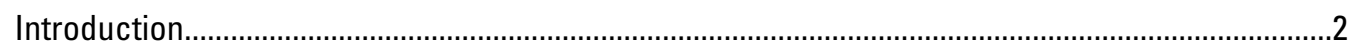

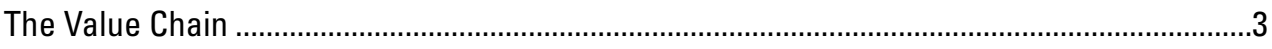

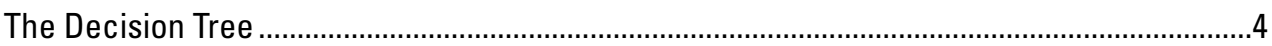

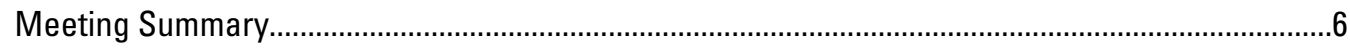

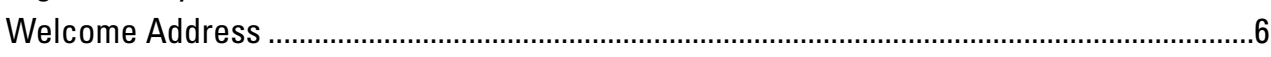

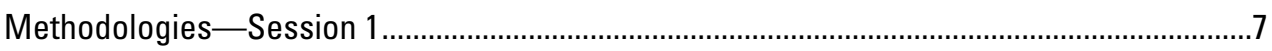

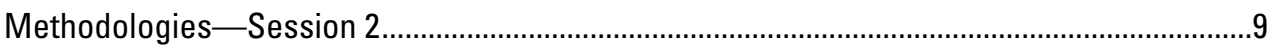

Introduction to Value Chains/Decision Trees and Processes Panel—Session 3....................11

Value Chains/Decision Trees Forum—Session 4 ………......................................................12

Value-Chain and Decision-Tree Working Groups..................................................................13

Group 1-Effect of Increasing Temperatures on Human Health...................................13

Group 2-Flooding — Mitigating. Managing, and Avoiding Impacts to Safety and Property Damage..........................................................................................14

Group 3-Harmful Algal Blooms-Effects on Human Health, Recreation,

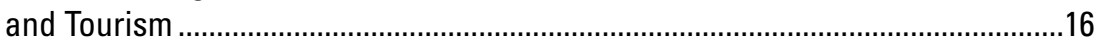

Group 4-Energy and Mineral Supply—Mitigating, Managing, and Avoiding Impacts of Shortfalls on the Economy............................................................... 18

Group 5-Effects of Natural Hazards on Transportation Systems-Effects on Mobility, Safety, and the Economy.................................................................22

Open Discussion-Working Group Approaches to Developing Value Chains

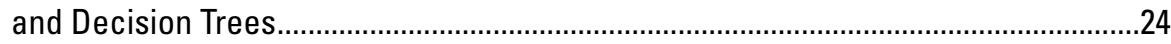

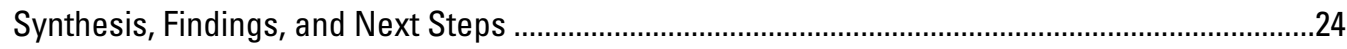

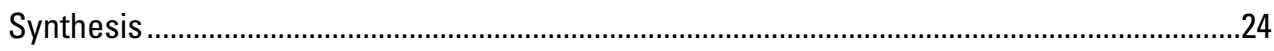

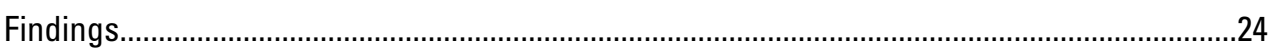

Next Steps

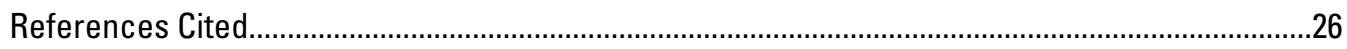

Glossary

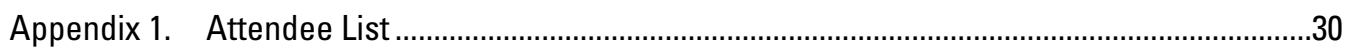

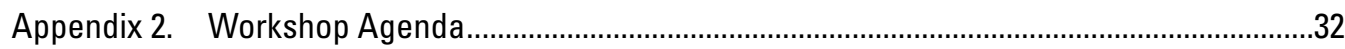

\section{Figures}

1. Graph showing GEOValue Community events (2010-17) ..................................................

2. Diagram showing Earth observation information value chain..........................................

3. Diagram showing Earth observation decision tree.....................................................

4. Diagram showing effects of increasing temperatures on human-health

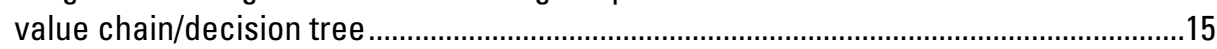

5. Diagram showing flooding: mitigating, managing, and avoiding impacts to safety and property damage value chain/decision tree. 
6. Diagram showing harmful algal blooms (HAB): effects on human health, recreation, and tourism value chain/decision tree.

7. Diagram showing energy and mineral supply: mitigating, managing, and avoiding impacts of shortfalls on the economy value chain/decision tree

8. Diagram showing effects of natural hazards on transportation systems: effects on mobility, safety, and economy value chain/decision tree.

\section{Tables}

1. Group 1 participants

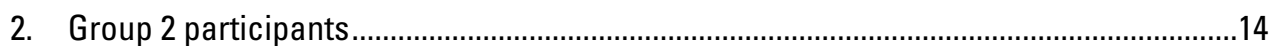

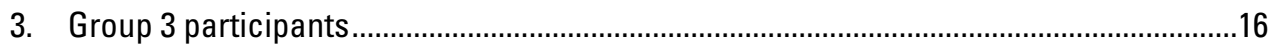

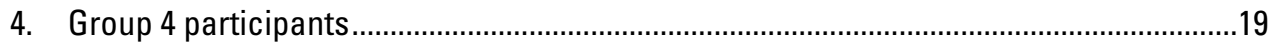

5. Group 5 participants...................................................................................................22

1.1. GEOValue side event attendee list, Washington, D.C., October 23-24, 2017 ...................30

\section{Abbreviations}

3D three dimensional

CRCSI Cooperative Research Centres for Spatial Information

EARSC European Association for Remote Sensing Companies

EO Earth observations

ESA European Space Agency

FAA Federal Aviation Administration

GEO Group on Earth Observations

GRACE Gravity Recovery and Climate Experiment

HAB harmful algal bloom

NASA National Aeronautics and Space Administration

NOAA National Oceanic and Atmospheric Administration

RFF Resources for the Future

USGS U.S. Geological Survey

VOI value of information 


\title{
Demonstrating the Value of Earth Observations- Methods, Practical Applications, and Solutions- Group on Earth Observations Side Event Proceedings
}

\author{
By Francoise Pearlman, ${ }^{1}$ Collin B. Lawrence, ${ }^{2}$ Emily J. Pindilli, ${ }^{2}$ Denna Geppi, ${ }^{3}$ Carl D. Shapiro, ${ }^{2}$ \\ Monica Grasso, ${ }^{3}$ Jay Pearlman, ${ }^{1}$ Jeffery Adkins, ${ }^{3}$ Geoff Sawyer, ${ }^{4}$ and Alessandra Tassa ${ }^{5}$
}

\section{Executive Summary}

The U.S. Geological Survey, the National Oceanic and Atmospheric Administration, the European Association for Remote Sensing Companies, and the European Space Agency in coordination with the GEOValue Community hosted a side event to the Group on Earth Observations Plenary on October 23-24, 2017, in Washington, D.C. The workshop, entitled "Demonstrating the Value of Earth Observations: Methods, Practical Applications and Solutions," brought together more than 60 international experts including economists, scientists, and engineers to consider the state of the science and applications of valuing Earth observations (EO).

This 2-day workshop built upon previous activities developed under the GEOValue initiative. This workshop brought together expert analysts from multiple disciplines and backgrounds who are developing methods to identify and measure the value of information generated from the use of satellite and in-situ data. The mix of government agencies, international financial institutions, and independent consultants who participated in the workshop blended to develop a rich mix of views, approaches, and outcomes.

During the first part of the workshop, the focus was on the latest science in valuing EO. A number of methodologies were described. Approaches generally assess the societal benefits of specific actions (for example, investments in EO). Some methods focus on broad measures of economic activity (for example, gross domestic product) or methods to assess total economic value such as contingent valuation surveys. Alternatively, use-case approaches (a use case is defined as an evaluation in which one or more decisions, applications, or other uses of data, information, and information products are specifically considered) start with the specific actions and

\footnotetext{
${ }^{1}$ FourBridges.

${ }^{2}$ U.S. Geological Survey.

${ }^{3}$ National Oceanic and Atmospheric Administration.

${ }^{4}$ European Association of Remote Sensing Companies.

${ }^{5}$ European Space Agency.
}

how information is used to support decision making and affect outcomes.

The second part of the meeting was focused on the use and development of value chains and decision trees. A value chain can be defined as the set of value-adding activities that one or more organizations perform in creating and distributing goods and services. In terms of EO, the value chain approach can be applied to consider societal benefits of the data and assess the value of data and data features. The EO value chain considers the geospatial data sources and the processing of the data into value added information to be incorporated into decision-support systems, leading to decision makers' actions. To understand the value of EO, one would also need to recognize the demand side of the equation or how $\mathrm{EO}$ benefits users. Extending the value chain concept and incorporating tenets of Bayesian decision making, a decision tree would include one or more use cases. The value provided by the marginal increase in information could flow from one or several parts of the supply side of the value chain. The decision tree is based on the premise that information has no value if it is not used in at least one decision. By connecting the value chain and the decision tree, a framework is created that allows for conceptualizing the value of EO in its many uses. One can then apply economic techniques to monetize the marginal benefit of an outcome with information versus one without.

A third part of the meeting applied the value chain and decision-tree frameworks to five specific thematic areas, each with the focus of using information for a decision point:

- Effect of increasing temperatures on human health;

- Flooding-Mitigating, managing, and avoiding impacts to safety and property damage;

- Harmful algal blooms-Effects on human health, recreation, and tourism;

- Energy and mineral supply—Mitigating, managing, and avoiding impacts of shortfalls on the economy; and

- Effects of natural hazards on transportation systemsEffects on mobility, safety, and the economy. 
During the working session, five separate groups worked to define and delineate the value chains and decision trees associated with each topic, discussing the related challenges and data needs. The outcomes were reported back to the full group. Because of the complexity of the topics, most groups first identified a network of value chains and then narrowed the scope to develop a single value chain to address their group's topic. Although they worked separately and on different topics, the groups came to similar conclusions, concurring that the value chain and decision-tree frameworks are very effective for informing quantitative impact assessments and developing a relatable narrative to assist the public in understanding the link between $\mathrm{EO}$ and citizens.

\section{Major Findings}

Finding 1.- It is critical that improved understanding of the value of EO be developed.

Finding 2.-The understanding of the value of EO is facilitated by a description or narrative clearly explaining the basis for societal benefits from EO and a quantified estimate of the value in monetary or nonmonetary terms.

Finding 3.-Narratives that explain the basis of the societal benefits from the use of EO need to provide a clear and relatively simple explanation of how EO can create an improved societal outcome.

Finding 4.- Value chains and decision trees can be useful tools in understanding the value of EO.

Finding 5.-Use cases help advance the state of the science of valuing information.

Finding 6.-Innovations in quantifying the value of information are needed.

Finding 7.-Group on Earth Observation provides an institutional pathway for engaging an international community for the research and application of valuing EO.

\section{Next Steps}

The workshop was successful in highlighting and understanding value chains and decision trees relating to EO. Participants supported the ongoing role and importance of the GEOValue Community. Initial value-chain decision-tree frameworks were developed for five topics and will continue to be worked with different subsets of groups. The next GEOValue Community meeting is expected to further consider this methodology and tackle other common issues with valuing EO. The following future directions will enhance efforts to develop improved understanding of the value of EO.

1. Innovative approaches need to be discovered and leveraged.

2. The GEOValue community needs to continue and be strengthened.
3. More case studies should be developed to cover as wide a range as possible of thematic, product, and geographical dimensions.

4. The different methodologies should continue to be developed and compared to explore the viability, effectiveness, and best practices for the use of value chains and decision trees in analyzing the value of EO.

5. Practical illustrations of value-chain and decision-tree applications through results from case studies should be shared and discussed at a future GEOValue workshop.

6. The international, interdisciplinary dimensions should continue to be developed to draw out the richness of case analyses.

\section{Introduction}

The U.S. Geological Survey (USGS), the National Oceanic and Atmospheric Administration (NOAA), the European Association for Remote Sensing Companies (EARSC), and the European Space Agency (ESA) in coordination with the GEOValue Community hosted a side event to the Group on Earth Observations (GEO) Plenary on October 23-24, 2017, in Washington, D.C. The workshop, entitled "Demonstrating the Value of Earth Observations: Methods, Practical Applications and Solutions," brought together an international, interdisciplinary group of economists, scientists, and engineers to consider the state of the science on valuing Earth observations (EO). This report provides a summary of the workshop as well as a set of future directions for advancing the science. The workshop was video recorded and can be found at Group on Earth Observations (2017a, 2017b, 2017c).

The value of information (VOI) has been a subject of interest for decades with rich literature focused on the use of weather information for agriculture production and management as reported by Johnson and Holt (1986), Adams and others (1995), Lave (1963), Sonka and others (1987), Babcock (1990), Pielke (1995), Nordhaus and Popp (1997), and Hersh and Wernstedt (2002). These studies tie the input of additional information to an increase in economic value. Nordhaus (1986) derived the VOI for hurricane data in 1986 and is one of the most often cited for estimating VOI. In recent years, understanding the value of $\mathrm{EO}$ has become increasingly important because budget constraints require enhanced understanding of return on investment.

The GEOValue Community (http://www.geovalue.org/) was formed to bring together a wide range of natural science, social, economic, management, and communication experts to share information, collaborate, and build capacity to understand the benefits from geospatial and environmental information for complex socioeconomic decisions. The GEOValue Community has held several meetings over the course of the last decade. See figure 1 for the number and types of meetings 
held by the GEOValue Community since 2010. The workshop described in this report was designed to share the latest science and applications of valuing EO and to advance the state of the science by considering a set of EO applications and the benefits of information for these uses. The workshop program was therefore divided into three activities: (1) a series of presentations on recent studies on the value of EO; (2) a panel and open discussion on the value-chain/decision-tree approach; and (3) facilitated break-out sessions to brainstorm and develop value chains/decision trees for a set of EO informed decisions.

The first part of the workshop focused on the latest science in valuing EO. Several methodologies were described. Approaches generally assess the societal benefits of specific actions (for example, investments in EO). Some methods focus on broad measures of economic activity (for example, gross domestic product) or methods to assess total economic value such as contingent valuation surveys. Alternatively, use-case approaches start with the specific actions and how information is used to support decision making and effect outcomes.

Presentations included international case studies and provided theoretical underpinnings and specific application of VOI analysis. A cross-sector assessment of the Copernicus Programme was presented. Other presentations illustrated differing methodologies with specific case studies including early warning systems for weather information in France, an analysis of the value of EO in Australia, the marginal value of three-dimensional (3D) geo-information, the value of Landsat moderate EO, a case study on the value of a dedicated national spatial data agency in Albania, a case study on the use of radar imagery to help icebreakers navigate in the Baltic Sea, and the use of EO for mitigating the impacts of drought on agriculture. After a morning of presentations on methodologies, the workshop was narrowed to focus on value-chain and decision-tree analytic frameworks.

\section{The Value Chain}

A value chain can be defined as the set of value-adding activities that one or more organizations perform in creating and distributing goods and services (Longhorn and Blakemore, 2007). The concept was initially introduced by Porter (1985) and is widely used in evaluating business management and profitability. By understanding the ultimate "value" of a product and the components along the value chain, businesses can consider how to optimize processes. In terms of EO, the valuechain approach can be applied to consider societal benefits of the data and assess the value of data and data features. The EO value chain considers the geospatial data sources and the processing of the data into value added information to be incorporated into decision-support systems, leading to decision makers' actions. Workshop participants believed that it may be best to start from the end (from the users) and approach the value chain in reverse order. The supply side of a generic EO value chain can be illustrated by figure 2 ; to consider the users, a decision tree is one approach to conceptualize the demand side and is illustrated in figure 3.

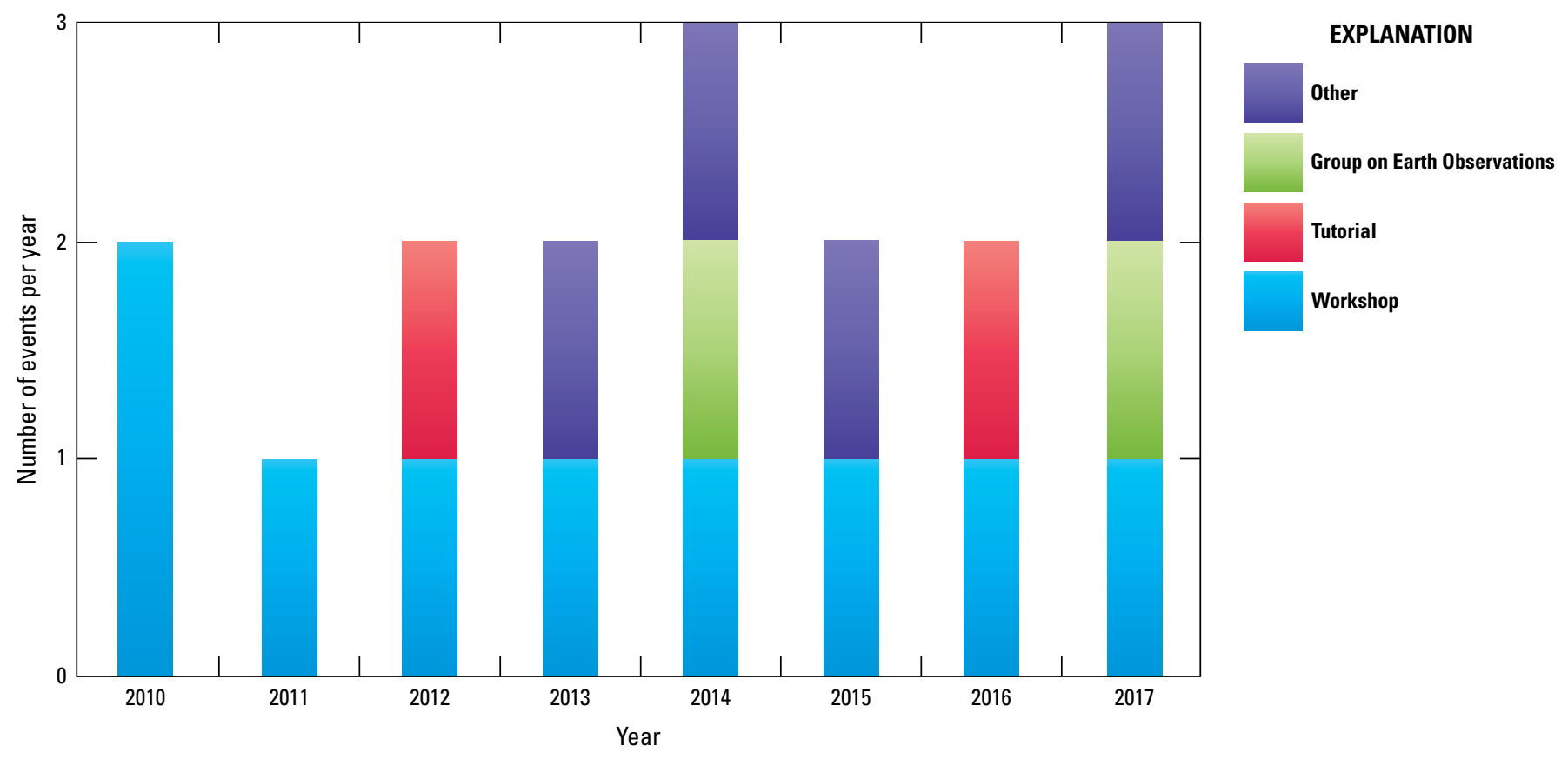

Figure 1. GEOValue Community events (2010-17). 


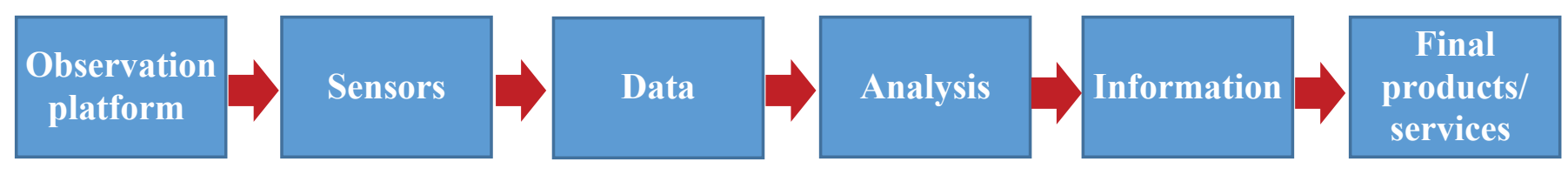

Figure 2. Earth observation information value chain.

\section{The Decision Tree}

To understand the value of EO, one would also need to recognize the demand side of the equation or how EO benefits users. Extending the value-chain concept and incorporating tenets of Bayesian decision making, the following represents a generic demand side of a value chain for EO or a decision tree. There could be one or more "decisions" or other uses of data, information, and information products (often termed "use case"). The value provided by the marginal increase in information could flow from one or several parts of the supply side of the value chain (fig. 2).

The decision tree is based on the premise that information has no value if it is not used in at least one decision. Therefore, the purpose of the decision tree is to consider the types of decisions made using information and compare scenarios with and without information. A simplified form is assumed where the with information is reality and decision pathways are known. The without-information scenario, or counterfactual needs to be considered. One identifies the potential alternative decision pathways, the outcomes of those pathways, the probability of a decision maker choosing any pathway given the next best information, and the monetized value of each decision pathway. Each of the decision points in figure 3 illustrate the simplified derivation of the value of information. To quantify the value of information under these assumptions the following formula would estimate the value:

$\left[\left(P^{*} \times M^{*}\right)\right]-\left[\left(\left[P_{1} \times M_{1}\right]+\left[P_{2} \times M_{2}\right]+\left[P_{3} \times M_{3}\right]\right)\right]=V O I$

where

$$
\begin{array}{cl}
P & \text { is the probability of a given decision pathway, } \\
M & \text { is the monetized value of a given decision } \\
\text { pathway, and } \\
\text { VOI }
\end{array}
$$

It should be noted that this formula is associated with figure 3, which assumes that the decision pathway for the with information is known (i.e., there is no uncertainty in the with information case). The illustration has three possible decision pathways, there may be more or less decision pathways that could be considered in estimating the value of information. Finally, this estimates a one-time or annual value, it does not consider the net present value of a decision over time.

By connecting the value chain and the decision tree, a framework is created that allows for conceptualizing the value of EO in its many uses. One can then apply economic techniques to monetize the marginal benefit of an outcome with information versus one without. At the workshop, an expert panel discussed the use of the value-chain/decision-tree framework. The panelists also introduced questions about the type of information needed to develop value chains/decision trees. Panelists discussed a wide range of applications that have been considered using a value-chain/decision-tree framework including human health, ecosystems, emergency management, and resource allocations. During the workshop, three different perspectives were examined in this regard:

- Product value chains/decision trees (analyzing the impact of a single information product),

- Thematic value chains/decision trees (analyzing the impact in a thematic area [for example, flooding] from a suite of products), and

- Market value chains/decision trees (analyzing the impact of products within the context of the market sectors within which they are used).

After the conceptual review of the value-chain/decisiontree framework, the workshop focused on the development of value chains/decision trees for five specific topics:

1. Effect of increasing temperatures on human health;

2. Flooding-Mitigating, managing, and avoiding impacts to safety and property damage;

3. Harmful algal blooms (HABs) - Effects on human health, recreation, and tourism;

4. Energy and mineral supply—Mitigating, managing, and avoiding impacts of shortfalls on economy; and

5. Effects of natural hazards on transportation systemsEffects on mobility, safety, and economy.

To address these five topics, workshop participants divided into small working groups to define and develop the value chains/decision trees associated with each topic. During these breakout sessions, participants discussed the related challenges and data needs, and presented their group's results when workshop participants reconvened. From the outcomes shared by each group, it was evident that the descriptions of the value chains/decision trees stimulated interesting insights into the multiple impacts of EO data to society and the international economy. 


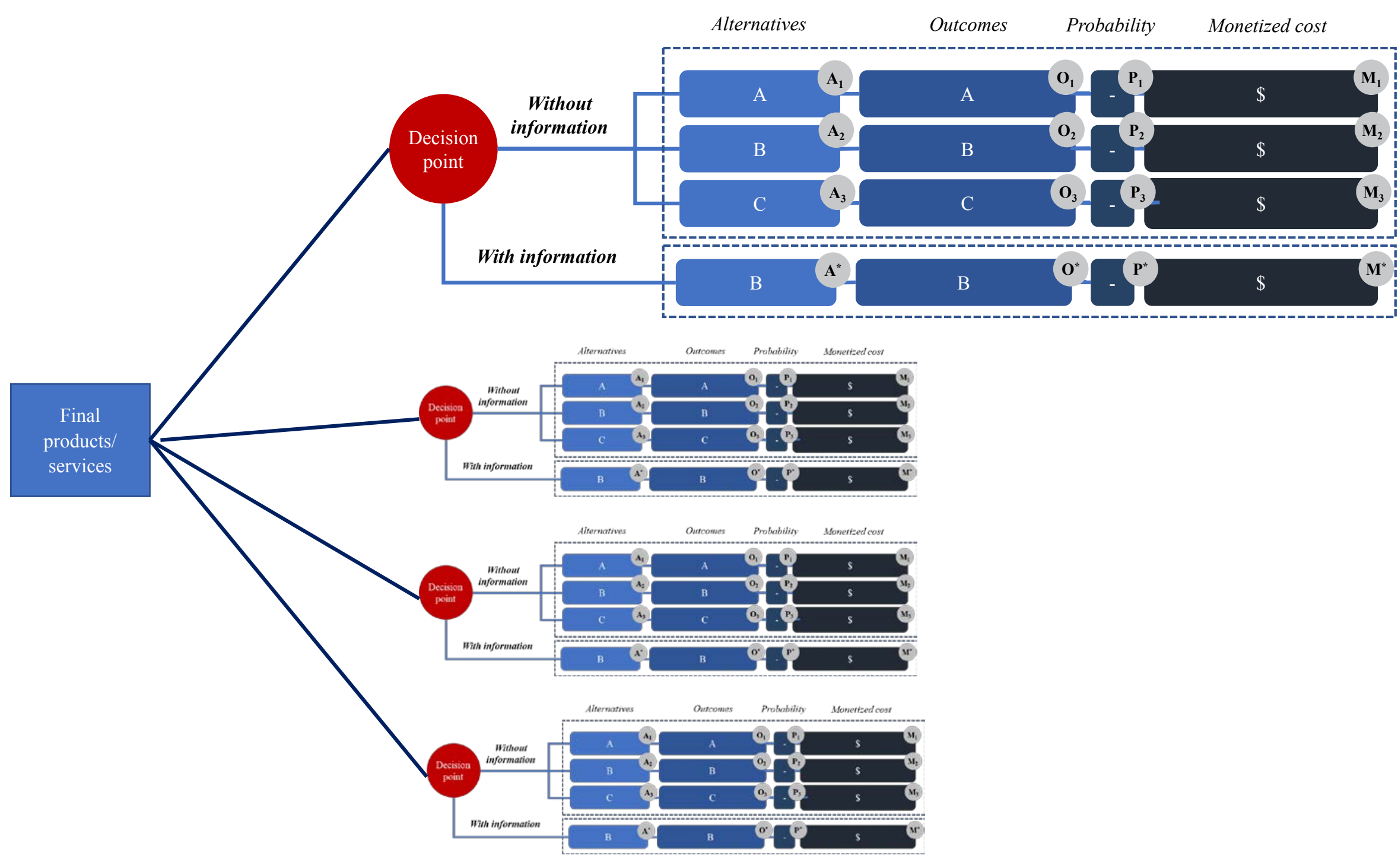

Figure 3. Earth observation decision tree. 
The use of EO in decision making results in economic impacts to society; however, these impacts are difficult to quantify. The goal of this workshop was to identify methods and solutions needed to develop robust and reliable estimates of the value of EOs in decision making. This is needed to assess and prioritize investments in EO research, development, and operations. To advance the state of the science and test a value-chain/decision-tree framework, five use cases were examined to understand the crosscutting methodological elements for assessment.

The long-term objective of this workshop is to lay a foundation for the consistent valuation of $\mathrm{EO}$ within and across government agencies and other organizations. This document describes the workshop proceedings, the results of the breakout activity, and significant findings and future directions for the GEOValue Community. The main body of the report provides proceedings from the workshop in the next "Meeting Summary" section. After that section, findings and next steps are provided.

\section{Meeting Summary}

The "Demonstrating the Value of Earth Observations: Methods, Practical Applications and Solutions" workshop was held as a GEO Plenary side event on October 23-24, 2017, in Washington, D.C. The 60 participants attending the workshop were primarily from U.S. academia and government backgrounds, including the USGS, NOAA, National Aeronautics and Space Administration (NASA), U.S. Environmental Protection Agency, East Carolina University, and the University of New Mexico. Nongovernmental organizations were also represented, including Resources for the Future (RFF). Multiple private and international organizations were also represented, including the World Bank, ESA, EARSC, the European Commission, as well as private companies such as Esri and ACI Consulting. Participants represented multiple domains including natural sciences, social sciences, and economics. A list of attendees and their contact information is provided in appendix 1, table 1.1. The meeting was facilitated by Aimee Cooper (USGS) pursuant to the agenda (the detailed agenda is available in appendix 2).

\section{Welcome Address}

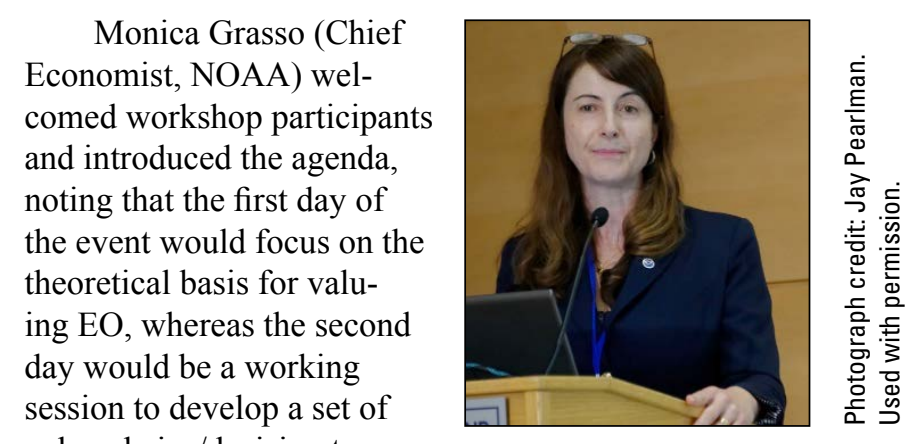
value chains/decision trees. Grasso noted the importance Monica Grasso, NOAA. to NOAA of valuing EO considering NOAA's role in collecting EO.

Carl Shapiro (Director of the Science and Decisions Center, USGS) noted that the USGS operates in a multidisciplinary environment. Because many government agencies make decisions in this environment, it is important to communicate and demonstrate the use and value of scientific informa-

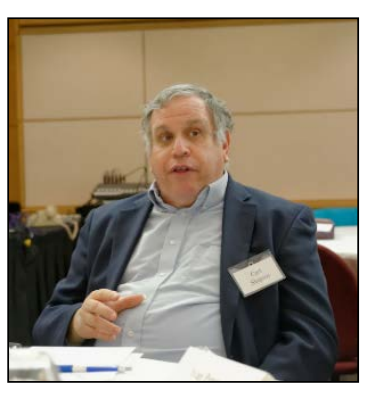

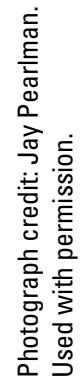
Carl Shapiro, USGS. tion within and across these environments. He added that during the morning session, the invited presenters would address methods and practices; then together, participants would look at the value-chain/decisiontree framework and how to identify the source of value. Shapiro explained that the second day would be focused on applications. Five examples that are important to the attendees and the USGS would be considered in terms of the valuechain/decision-tree perspective. Lastly, Shapiro discussed how Monica Grasso and he would moderate a discussion of strategies for valuing future $\mathrm{EO}$ to identify future directions for the community.

\section{Alessandra Tassa} (ESA) welcomed participants next. The ESA builds Earth observing satellites and operates them (for example, the Copernicus Sentinels, CryoSat, Gravity field and steady-state Ocean Circulation Explorer) or hands them over to the European Organization for the Exploration of Meteo-

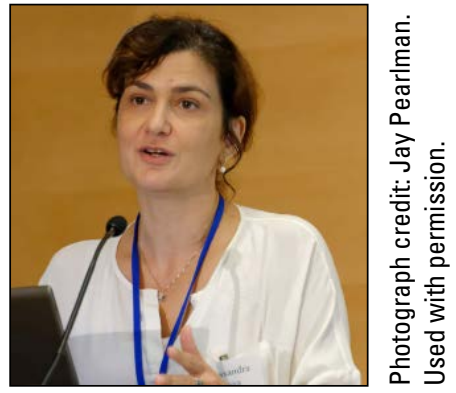

Alessandra Tassa, ESA. rological Satellites or the European Commission. As a provider, ESA is an enabler of the benefits from EO; however, Tassa mentioned that ESA knows 
too little about what users do with their data. This is especially true for data distributed under a completely free and open data policy like the ones from the Copernicus Sentinel satellites.

She stated that there is pressure to provide evidence about the contribution of satellite data to the economy, addressing the value chain/decision tree from satellites to citizens. Highlighting the link between citizens and satellites has been compelling in demonstrating the value of their data.

Finally, Geoff Sawyer (EARSC) welcomed participants. He explained that EARSC represents the space and technology industry. Sawyer discussed how most studies to date have been based on topdown macroscale analysis. EARSC, with the ESA, has been working on a bottom-up value-chain approach based on a single product leading to

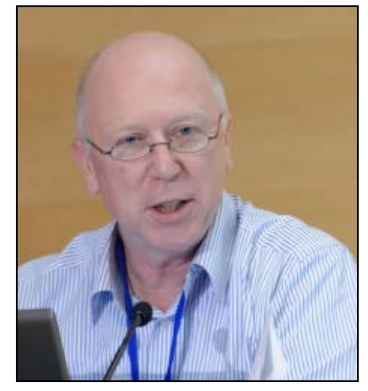

Geoff Sawyer, EARSC. an actionable decision. He added that this has been presented at the GEO work plan symposium in Pretoria, South Africa, leading to the request to establish a side event in Washington, D.C. He was happy that this had led to the joint event starting that day. Lastly, he discussed his intention for continued engagement and referenced the GEOValue Community.

After the introductions from the workshop organizers, participants briefly introduced themselves and described their interest in attending the event.

\section{Methodologies-Session 1}

Steve Ramage (GEO Secretariat) introduced the first session on methodologies, which included the following presentations:

- Andreas Veispak, "Demonstrating the Value and Benefits of the Copernicus Programme" (Veispak, 2017).

- Alan Smart, "Estimating the Value of Earth Observation-Methodologies" (Smart, 2017).

- Stephane Hallegatte, "Simple Assessments of the Benefits from Early Warning Systems and Stronger HydroMeteorological Systems" (Hallegatte, 2017).

- Andy Coote, "Value Chain and Cost-Benefit Analysis: Applied to 3D Geo-Information" (Coote, 2017).

Veispack presented a study on demonstrating the value of Copernicus (Veispak, 2017). Veispack is head of the European Commission's Space Data for Societal Challenges and Growth Unit. The European Copernicus program monitors the environment and security using six dedicated Sentinel satellites and a set of contributing missions. It provides six Copernicus services (land, marine, atmosphere, climate change, emergency management, and security). All data are distributed following a free, full, and open data policy. The program has cooperation agreements with peer-to-peer data hubs in the United States and Australia. They have a budget of 4.3 billion euros for 2014 through 2020.

The value chain spans the space and in-situ data provided by the ESA, the European Organization for the Exploration of Meteorological Satellites, the Copernicus services, and others. Downstream services are tailored for users. The European Commission's aim is to optimize the benefits that space technologies bring to society and the wider European economy. As budgetary constraints grow, policymakers put greater emphasis on the usefulness of space technologies.

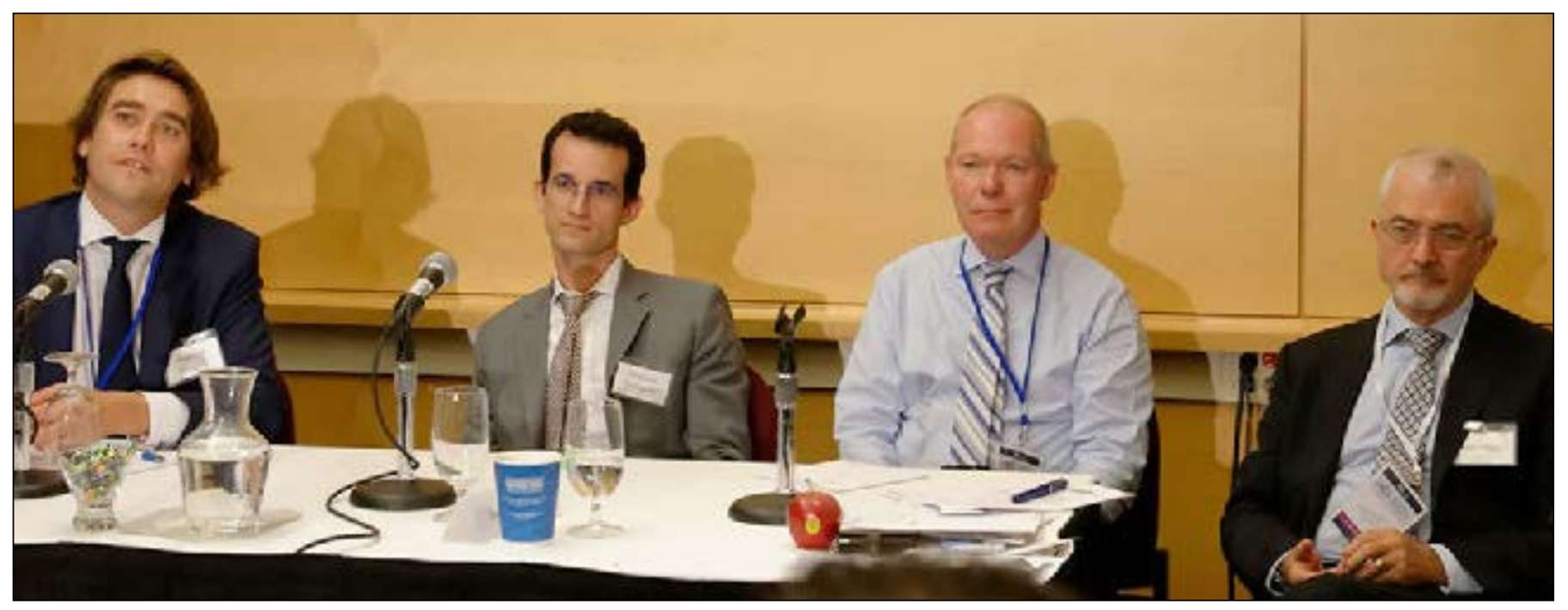

Panel 1—From left to right: Andreas Veispack, Stephane Hallegatte, Andrew Coote, and Alan Smart. 
Three complementary approaches are used to develop value chains: case studies, market reports, and ex-ante evaluation. The bottom-up case studies developed by EARSC and ESA are used to illustrate this strategy. The resulting estimates are robust and quite specific; however, extrapolation is not always easy, and the resulting estimates are conservative and labor intensive.

The second approach focuses on market reports and includes the following phases:

- Characterizing the value chain,

- Mapping the players in the value chain,

- Selecting a representative sample of users,

- Engaging sampled users in direct interviews, and

- Extrapolating results to all users.

The third approach is an ex-ante benefit evaluation. An example of this approach centers on impact pathways for crop monitoring. A methodology is designed for each impact, including hypotheses on uptake, projected growth of the market, and societal valuation. The Copernicus benefits are estimated for each impact, and the results are aggregated. Ex-ante estimates are comprehensive (including economic, societal, and environmental benefits) and useful for decision making; however, many hypotheses are needed, and the reliability decreases with long time horizons. Some of the challenges are associated with double counting across sectors, and long-term unknowns (for example, how do you quantify time series value and how do you establish a price based on autonomy and independence?).

Alan Smart is a senior associate for ACIL Allen Consulting, in Sydney, Australia. He gave a brief overview of the methodologies associated with estimating the value of EO and discussed an example from Australia (Smart, 2017). Smart distinguished between the use value, which is direct, application related, and where someone makes use of the information; and the nonuse value, which is subjective, and is associated with such concepts as satisfaction and preservation of a good or service. The Earth Observation from Space value chain starts with data acquisition; includes processing, storage/archiving, and extracting information; and concludes with user products and services. Users are grouped into categories such as government, industry, and research.

One approach for estimating the value of EO is to consider how the use of this information can shift "production possibility frontiers," increasing total production in the economy. The economic contribution of EO can be estimated by comparing total production in a reference case that includes production associated with EO to a counterfactual case that excludes it. The benefit attributable to EO is the difference in total production under the two scenarios.

Using input-output models, direct and indirect impacts can be estimated; these models are limited, however, in that they are static and do not account for the ability of the economy to adapt to changes over time. This limitation can be overcome by using dynamic computable general equilibrium models, which account for the ability of the economy to adapt to change and are better for assessing the productivity changes associated with the use of EO.

Smart concluded by presenting the report entitled "The Value of Earth Observations from Space to Australia" (ACIL Allen Consulting, 2015) which includes direct and indirect effects. This report highlighted the importance of weather forecasts for farmers, ocean observations for the Great Barrier Reef, and the price of water for improved water management.

Stephane Hallegatte presented "Simple Assessments of the Benefits from Early Warning Systems and Stronger HydroMeteorological Systems" (Hallegatte, 2017). Hallegatte works in the Global Facility for Disaster Reduction and Recovery program at the World Bank. He opened his presentation by noting that the value of a weather forecast depends on who uses it and for what purpose. He stressed the complexity of assessments, which includes the multiplicity of timescales, multiplicity of actors, and multiplicity of use. For example, a flood brings different and unexpected decision-making responses from people, such as whether there is time to move the piano or the vacuum cleaner. For this reason, interaction with data users needs to be a priority during design.

A framework can be used for assessing the value of early warning systems to determine the economic loss corresponding to a 30-minute warning, 1-hour warning, and so on, comparing the expected losses under each scenario. Loss reductions (that is, economic value) do not increase linearly with the lead time or the quality of the forecast. Imperfect forecasts are difficult to use, especially if they result in false alarms, which can result in citizens ignoring future alarms. The value of a forecast depends on the cost and benefit of early actions and must account for unexpected human behavior.

Andrew Coote presented the "Value Chain and CostBenefit Analysis: Applied to 3D Geo-Information" (Coote, 2017). Coote is a consultant for ConsultingWhere Ltd. He discussed how the quantification of socioeconomic benefits is increasingly critical in making the business case for EO projects. Value-chain analysis and cost-benefit analysis are well developed and understood general methodologies, which can be applied where geoinformation is the primary deliverable. These methodologies work best when applied to welldefined use cases with good sources of primary evidence. The VOI should not be confused with the value of benefits from policies, systems, or both, that use it in decision making (the apportionment problem). There is almost always alternative evidence to support decisions, and this counterfactual scenario must be considered in valuation; an information source is only worth the "delta" in value between it and the next best alternative.

The Environmental Value Reference Inventory (https://www.evri.ca/) is a database with empirical studies on the economic value of environmental assets that demonstrate the use of a wide range of methodologies. The 3D geoinformation case study was undertaken for EuroSDR (a research body funded by National Mapping and Cadastral Agencies) 
to identify potential use cases and apply either a value-chain analysis or cost-benefit analysis. For each use case, a workshop approach was used to identify the actors, the information they produce, and the processes where value is added. The resulting value chain can be very complex.

Cost-benefit analysis is commonly used to help assess the business case for investment in a project or proposal. It provides a means of objective comparison between projects with different costs, benefits, and durations. Three methods can be used on the benefits side: cost avoidance, case-study evidence, and benefits transfer. Coote concluded his remarks by stating that we are not alone in seeking solutions to information quantification, and we must learn from environmental economists and transport engineers. Databases similar to the Environmental Value Reference Inventory are needed for EO.

\section{Steve Ramage started a short discus- sion with the panelists. He discussed how there is a lack of agreement on how to measure the VOI. Is gross domestic product the right unit of measure? Others, but relatively few, use the concept of happiness (Bhutan, for example)

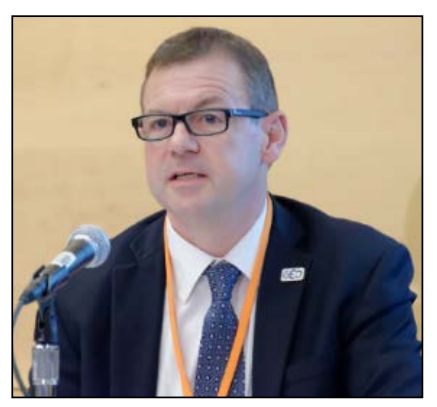 \\ Steve Ramage, GEO. as a measure of societal wellbeing. Virtually all of Google (and its high value) is infor- mation, but that is difficult to put on the balance sheet. \\ One panelist described the need to incorporate communi- cation experts into reporting the VOI. Another panelist men- tioned that one needs to focus on the audience (for example, decision makers) when developing narratives that explain the importance of EO. The panelists agreed that space technol- ogy, information technology, and other disciplines must work together to design and execute value of EO studies.}

\section{Methodologies-Session 2}

Steve Ramage introduced the second session, which included the following presentations:

- Rudy Schuster, "Communicating the value of Landsat Imagery Using Case Study Narratives" (Schuster and others, 2017).

- Aanchal Anand, "The Economic Value of Geospatial Information: An Albania Case Study" (Anand and Kelm, 2016).

- Rich Bernknopf, “A Decision Framework for Quantifying the Economic Value of Information (VOI) of Earth Observation: Case of the NASA Gravity Recovery

and Climate Experiment (GRACE) Enhanced Drought Severity Index” (Bernknopf, 2017).

- Geoff Sawyer, “A Bottom-Up Approach to Assessing the Value of Satellite EO Data" (Sawyer, 2017).

- Gerry Kinn, "Esri Perspective" (Cummens and Kinn, 2017).

\section{Rudy Schuster presented "Com- municating the Value of Landsat: Imagery Using Case Study Narratives" (Schuster and others, 2017). \\ Schuster is branch chief of the Social and Economic Analysis Branch at the USGS. His team has been working continuously with land remote sensing since 2007 to}

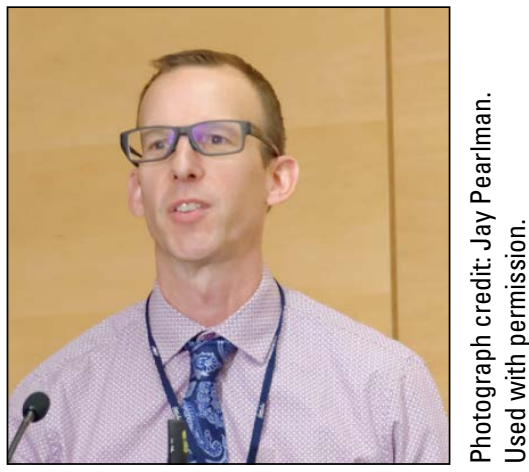

Rudy Schuster, USGS.

better understand the users, uses, and value of Landsat imagery. This project includes two main components: (1) surveys of Landsat imagery users in the United States and around the world and (2) case studies of the value of Landsat imagery. In total, 35 case studies on Landsat imagery use have been completed. These studies enrich understanding by providing context for the economic-benefit modeling. These case studies are a combination of investigative journalism, economic analysis, and quantitative evaluation of benefits. The case studies are organized into categories such as agriculture, forestry, technology, environment, humanitarianism, and water. Schuster described four specific examples: the search for water in West Darfur, innovations with Landsat, Landsat use by a forest management startup, and improving irrigation technology and grape and wine quality. It is important to complement communication of value by communicating the scientific context for those values.

\footnotetext{
Aanchal Anand presented on the "Economic and Financial Analysis of Geospatial Information: The Albania Case Study" (Anand and Kelm, 2016). Anand is a member of the World Bank Group, Global Land and Geospatial Team. Albania is a small country with many infrastructure problems. To address
}

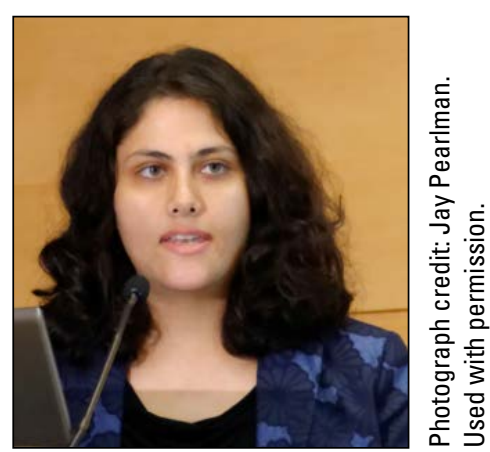

Aanchal Anand, World Bank Group. 
this, an integrated land and geospatial infrastructure project is being planned. Albania has a new dedicated national spatial data agency, Autoriteti Shtetëror për Informacionin Gjeospazial (translated "State Authority for Geospatial Information"). A component of this project is the creation of an integrated geospatial data system for Albania that is consistent with European standards for National Spatial Data Infrastructure. A first step is the acquisition of rights to use a cadastral dataset showing the ownership and other attributes of land.

Richard Bernknopf presented "A Decision Framework for Quantifying the Economic Value of Information (VOI) of EO: Case for a NASA Gravity Recovery and Climate Experiment (GRACE) Enhanced Drought Index" (Bernknopf and others, 2017). Bernknopf is a research professor in the economics department at the University of New Mexico, Albuquerque. He discussed how the U.S. Agricultural Act of 2014 identified the U.S. Drought Monitor (USDM) drought-severity classification to determine eligibility for drought disaster assistance. He described the linkage between the Gravity Recovery and Climate Experiment (GRACE) satellites and the USDM updating and production process. The GRACE satellites are used to monitor gravity to detect variations in the Earth's mass that are due to surface and groundwater storage changes. An ensemble of GRACE data and a catchment land surface model provide spatial water storage information. Three weekly GRACE data assimilation drought indicators are produced: surface soil moisture, root zone soil moisture, and groundwater. This study investigated the possibility of including GRACE indicators in the USDM and the usefulness of doing so. Information from the USDM is used by the U.S. Department of Agriculture in identifying regions for drought assistance.

A retrospective analysis of drought severity classifications was performed with and without GRACE data. A conceptual framework for estimating the socioeconomic value of GRACE information products was developed to evaluate the correlation between economic impact and the quality of geospatial information. Adding GRACE indicators reduced the number of high-value prediction errors. Statistical tests indicate that use of the three GRACE indicators in the drought monitor formulation increased the correlation between farm income/corn yield and the USDM. Also, goodness-of-fit criteria indicate statistically significant improvements.

Geoff Sawyer presented "A Bottom-Up Approach to Assessing the Value of Satellite EO Data" (Sawyer, 2017). He is the Secretary General of the EARSC, a membership-based, European trade association that provides business intelligence to their members, maintains knowledge of the industry, and promotes the industry and its capabilities. Sawyer discussed a study EARSC is performing on behalf of the ESA, quantifying the economic value created through the use of satellite data (see Sawyer and others 2016a and 2016b). In this study, a bottom-up, product-based approach is used working through the value chain. A counterfactual was obtained by considering the approach that was used before satellite imagery was available. The effort, in part, is to reach out to the level of the citizens so information regarding willingness to pay can be gathered.
Three case studies and reports were published (see http://earsc.org/library/media-material): Synthetic Aperture Radar imagery for ice-breakers in the Baltic Sea, optical data for forestry in Sweden, and Synthetic Aperture Radar interferometry providing ground displacement maps used to monitor gas pipelines in Netherlands. The following steps were used for each case study:

- Identify the information type, characterizing the value chain and how it benefits each user;

- Develop a model that allows the benefits to be assessed in economic terms;

- Assess how much of the value can be attributed to the use of satellite data;

- Identify factors that should be considered when extrapolating results; and

- Calculate the economic value for the product.

Sawyer noted that, where assumptions are made, they should be visible and validated as much as possible. The ability to measure the benefits in economic terms is also important. The value chain for ice breaker ships was discussed as an example. As the ice breaker guides ships through the ice to a port, delays and potential loss of cargo are reduced. The use of satellite data allows ice breakers to optimize the routes. As in all these cases, expert interviews are used to back-up desk research. Strong engagement of the primary user is a necessity to develop cases.

For this (and other) use cases, the contribution of imagery is shown in economic terms. A model is used to translate the reality into economic benefits. The model may be statistical as in the ice navigation case, financial as in the pipeline infrastructure case, or economic as in the forestry case. Further cases to be analyzed will enable an understanding of how generic or transferable each of these models will be. It is suspected that they are each highly specific to the case.

Gerry Kinn presented Esri's perspective on valuing EO methodologies (Cummens and Kinn, 2017). He discussed how a key part of working with the imagery and understanding the value of imagery is to be able to make the collected imagery accessible to the many users that need this information. Clearly, the value of imagery needs to exceed the cost of the investment. In the time before imagery, weather caused many fatalities because we did not have the ability to forecast the severity of storms. With imagery we can predict, assess, and provide information to make decisions in many situations.

Imagery archives are time machines that highlight circumstances that would have otherwise been missed. Users are not only interested in the imagery, or geographic information system, but also about using the two together. In the last couple of years, the publishing of maps has changed; for example, story maps have increased in popularity and are being produced every day. In their presentation, Kinn expressed the need to communicate the value of our work more effectively. He presented an example from the Chesapeake Conservancy 
showing that multiple scales of information are importantmedium-scale data can identify issues and even assist policymaking, whereas high-resolution data can be used to produce land-cover/land-use mapping and to inform site-specific actions. Remote sensing should be about image analysis, not technology because a lot of other contextual information is needed to complete the analysis.

Steve Ramage, moderator of session 2, started a short discussion with the participants. He asked why none of the presenters mentioned the financial services sector. Participants discussed how financial systems are very complicated and sharing information and making modifications to the system is difficult.

\section{Introduction to Value Chains/Decision Trees and Processes Panel-Session 3}

Emily Pindilli introduced the third panel, which introduced the value-chain/decision-tree framework. Panelists included the following:

- Tim Stryker

- Jeff Adkins, "Economic Valuation of NOAA Products \& Services: A Value Chain Approach” (Adkins, 2017)

- Jamie Kruse, "Valuation of Geospatial Information"

- Yusuke Kuwayama, "The Value of Value Chains for Evaluating the Socioeconomic Benefits of Earth Observations" (Kuwayama, 2017).

Tim Stryker described the use of EO at the USGS. He stated that EO is critical information infrastructure; we need to find better ways of characterizing its socioeconomic impacts because without it, lives will be lost, properties will be damaged, and the economy will be harmed. The U.S. Congress has directed the Office of Science and Technology Policy to develop a triennial National Plan for Civil Earth Observations, which prioritizes Federal agency activities in accordance with societal benefit. He emphasized the importance of a wide range of observing systems that together help generate forecasts, warnings, and other environmental analyses. For example, NOAA's tsunami-warning systems depend on data from NOAA's and various other agencies' observing systems. Because of these dependencies, it is important to be as granular as possible when characterizing the benefits of individual EO systems.

Jeff Adkins described economic valuation of NOAA products and services (Adkins, 2017). He is an economist working with NOAA's Chief Economist's team. Adkins has completed three studies on the VOI. He discussed how the value of goods and services produced by the Government lies in their use to change societal outcomes for the better. This is done by increasing productivity, lowering costs, and reducing losses from natural disasters. The value-chain approach that was described in this presentation reflects this relationship between the production of goods and services, the consumption of those goods and services, and the associated societal impacts.

In a simple model, observational platforms equipped with data-collecting sensors are launched and operated. The collected data have to be put into a usable format, stored, and made accessible to analysts. These data are then analyzed, producing information used to generate final products and services. Ongoing research supports all aspects of this work, from the design and manufacturing of observational platforms and sensors to the delivery of final products and services. The latter includes, for example, research in risk communication that helps users translate information into beneficial protective actions.

As we move into the demand part of the model, all the investments required to generate final products and services that generate value are measured against the impacts they have in improving societal outcomes. It is important to note that the demand side is different for each user. In assessing the value of a product or service, it is critical to know who uses it, how they use it, and how they benefit from its use. It is also important to know threshold values and degrees of change that are needed to change societal outcomes. An important question to ask is, "Where does an improvement in quality make a difference?"

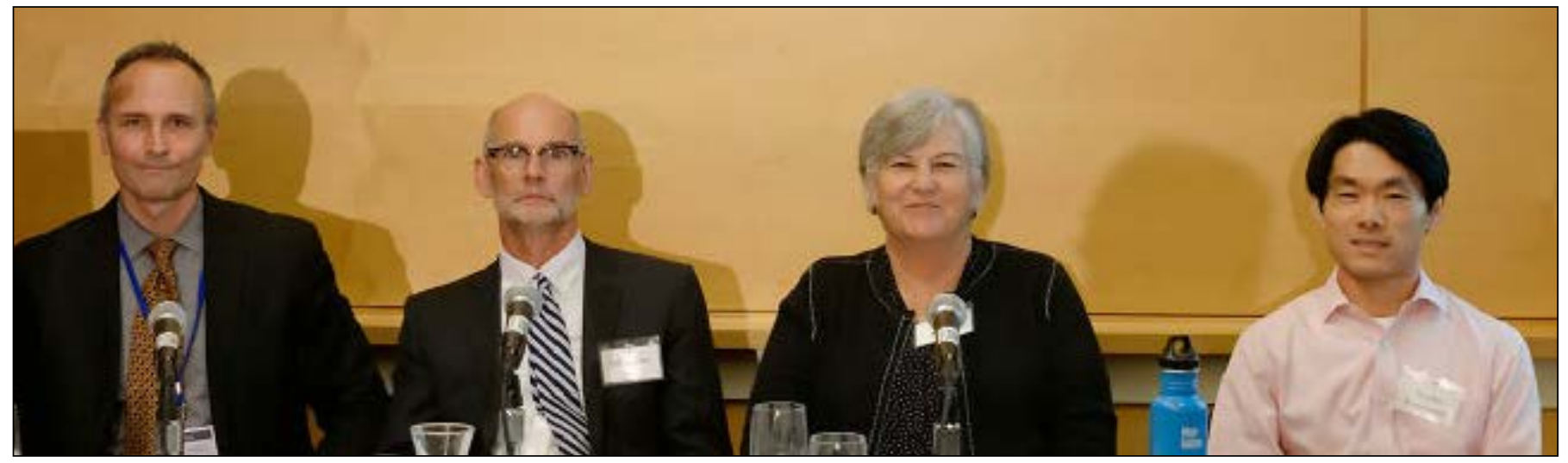

Panel 3 (left to right)—T. Stryker (USGS), J. Adkins (NOAA contractor), J. Kruse (East Carolina University), and Y. Kuwayama (RFF). 
Some of the products and services that NOAA produces are used directly by society. Others are used by intermediaries who produce value-added products and services that provide additional societal benefits. For example, NOAA's weather information and the underlying data and models provide the foundation for an additional $\$ 1.7$ billion in investments annually by the private weather information sector (U.S. Department of Commerce, 2014). In conclusion, Adkins added that it should be noted that research has value by itself, which creates another value stream.

Jamie Kruse is a professor at the East Carolina University Center for Natural Hazard Research. During her presentation, she addressed several questions:

- Do we all mean the same thing when we say valuation?

- What is being "valued?"

- Who is the VOI exercise for?

- And what is the purpose of the VOI exercise?

Developing a value chain is a multidisciplinary effort. Kruse discussed examples of decisions that were made in response to two natural disasters: Hurricane Matthew and the flooding of the Tar River in Greenville, North Carolina. Measurable differences in outcomes when geospatial information is included can be characterized by the following:

- Number of lives saved,

- Improved mental and physical health outcomes,

- Reduced property damage,

- Reduced disruption of economic activity, and

- Reduced business interruption.

In conclusion, Kruse discussed attribution of the valuethe incremental benefit of a specific decision-support system or dataset.

Yusuke Kuwayama is Director of Socioeconomic Studies for the Consortium for the Valuation of Applications Benefits Linked with Earth Science cooperative agreement between RFF and NASA. He shared a generic representation of a value chain for EO (Kuwayama, 2017). He then shared two examples. The first example addressed integrating GRACE and GRACE follow on data into river flow and flood forecasts. The value chain expresses the value of avoided flood damages from mitigation actions that would take place as a result of improved knowledge of precursor terrestrial water storage and subsequent flow forecasts for the Red River of the North. The actual historical information was compared with a current forecast and retrospective simulations. The second example is about climate observing systems, looking at the value of the proposed Climate Absolute Radiance and Refractivity Observatory system relative to current space borne systems.

Emily Pindilli, the Natural Resource Economics Lead at the USGS Science and Decisions Center moderated session 3. Pindilli started a short discussion with the participants on use cases. She discussed how the use cases provide an anchor to reality. Value chains/decision trees are useful frameworks to help understand where the value for data comes from, particularly regarding a policy perspective. During the discussion, there was a mention of the "garden of forking paths." For example, when considering a flood situation, the flood could be related to an ice dam or to another cause for high soil moisture; therefore, it is important to define the scope of decisions and benefits.

The question regarding why we do not see more value studies also came up. The panel discussed that these studies are primarily conducted at the end of the research process, once the objective systems have been funded. Through econometric analysis, we are able to extract information that we could not access otherwise. It was suggested during the panel discussion to look at the information that program managers need, what measurements are needed, and how products and services lead to a value tree.

In conclusion, the panel discussed approaches to identifying who is using your products. Taking the approach of an investigative reporter was suggested, and some strategies include looking at web statistics, and emailing questions and sending surveys to users.

\section{Value Chains/Decision Trees Forum—Session 4}

Jay Pearlman, Director, FourBridges, opened the fourth session, an open discussion. He stated that each team would be requested to provide a report addressing the basic structure of their value chain/decision tree, the challenges, the data requirements, and any unanswered questions. He discussed how with the transition

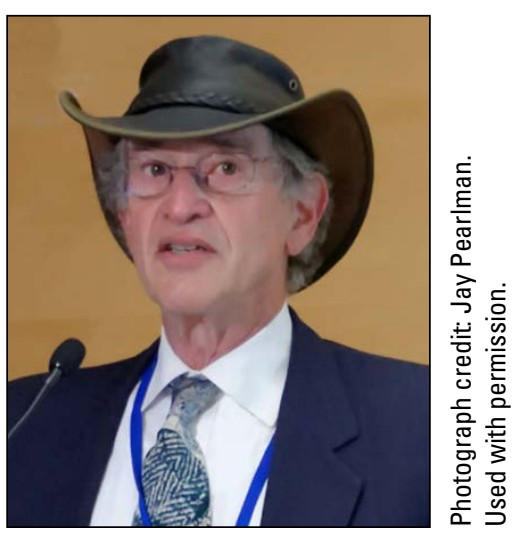

Jay Pearlman, FourBridges. toward open data, there is a change in paradigm. With this change, we find ourselves asking, "Who are the users and in what context are they using the data?" The value is easier to understand if it is measured within a particular sector. In all cases, the human is at the end of the value chain/decision tree.

Carl Shapiro suggested that one should start from the final products and services of the value chain and how they are used. He added that how we use the value chain is critical; not only do we have different methods between domains, but we also have different vocabularies. Jeff Adkins mentioned the need to focus on the production component to attribute value to inputs to production; "denial of data" experiments are quite useful because they illustrate how much worse off one would be without the data. 
Andrew Coote stated how EuroSDR approached the value chain systematically, decomposing the components according to a work breakdown structure and looking at the added value starting with the supply chain. Monica Grasso shared that she is looking for information that she can take back to the NOAA leadership. Alessandra Tassa discussed how we need to go beyond economic quantification and increase the emphasis on narratives that help decision makers understand and interpret results.

\section{Value-Chain and Decision-Tree Working Groups}

During this series of breakouts, each participant was assigned to one of five groups to develop a value chain/decision tree for a predetermined science application. Each group had 1 hour to consider its science application. In the next hour, each group identified the data needs associated with that same question. Each team worked with a trained facilitator to develop a value chain/decision tree and discuss data needs. They then summarized their findings and reported back to the entire group once the workshop reconvened. The discussion and findings of each of the groups are detailed below. The value chains/decision trees should be considered preliminary because they are largely based on the brainstorming from a short break-out session. The writing team revised value chains/ decision trees for clarity.

\section{Group 1-Effect of Increasing Temperatures on Human Health}

The first group included experts from diverse disciplines and perspectives (see table 1). They started at the end of the value chain/decision tree and discussed the effects of heat stress on the cardiovascular system during a heat wave. They interpreted the topic without an example of an existing product or set of information, rather as a what-if scenario. The group discussed a public-alert system as a near-term solution and a mitigation system for human health as a long-term solution.

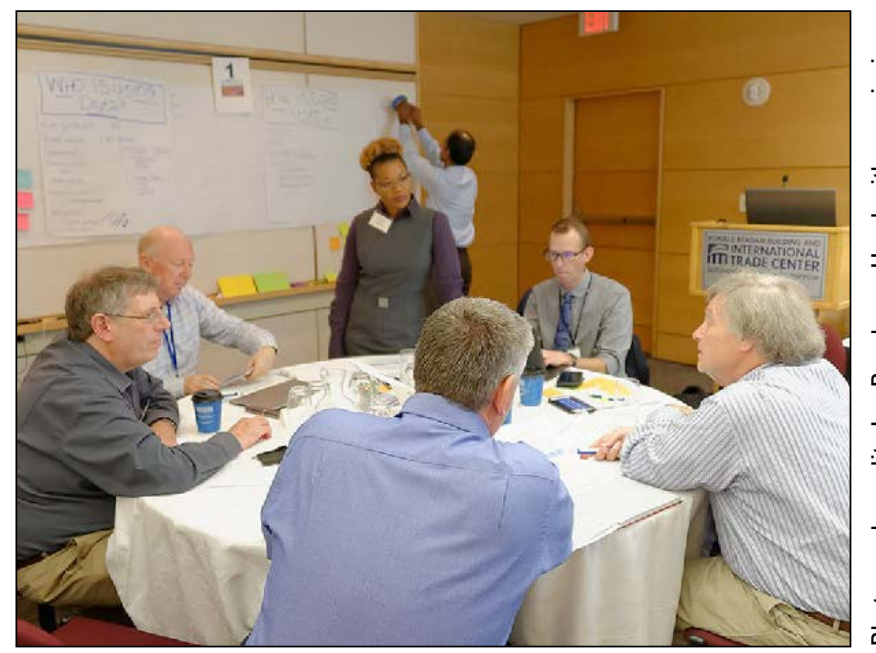

Table 1. Group 1 participants.

\begin{tabular}{ll}
\hline \multicolumn{1}{c}{ Name } & \multicolumn{1}{c}{ Organization } \\
\hline $\begin{array}{l}\text { Rich Bernknopf } \\
\text { Vankita Brown }\end{array}$ & University of New Mexico. \\
& $\begin{array}{c}\text { National Oceanic and Atmospheric } \\
\text { Administration. }\end{array}$ \\
John Firth & Acclimatise. \\
Pierre Glynn & U.S. Geological Survey. \\
Al McGartland & U.S. Environmental Protection Agency. \\
Bob O'Connor & National Science Foundation. \\
Rajendra Poudel & National Oceanic and Atmospheric \\
& Administration. \\
Geoff Sawyer & European Association of Remote Sensing \\
& Companies. \\
Rudy Schuster & U.S. Geological Survey. \\
\hline
\end{tabular}

${ }^{1}$ Facilitator.

${ }^{2}$ Rapporteur.

Regarding applications, the group discussed a traffic management system, which could minimize air pollution during a heat wave. The information needed for this application includes simplified material for use by decision makers and the general public. This would include graphics presenting data (heat stress days for example) and analysis and synthesis for various kinds of data into models (water data, medical data, and others). The challenges that the group discussed in this application include the following:

- Narrowing the scope,

- Defining indicators of success (different kinds of success),

- Performing user-centric design.

- Performing counterfactual management,

- Reducing the number of false positives,

- Multiple feedbacks,

- Short-circuits, and

- Garden of "forking paths."

Questions that arose during this discussion focused around defining the counterfactuals. The group asked, "How do you define the counterfactual?" It is a hypothetical system or do you plan for something that could happen. The group discussed potential examples, such as the management of the traffic light system, management of emergency vehicles, or both.

An initial value chain/decision tree for this topic is shown in figure 4. To the far left, the types of observation systems, both satellite systems and in-situ monitors, are listed that would provide useful information for reducing the impact of increasing temperatures on human health. Moving to the right 
are the specific types of data that the group discussed would be useful. The analytical tools such as weather forecasts are the next step in the value chain/decision tree. The decision-ready information and the final information product are identified next. This is the complete supply side of the value chain for this topic.

The breakout group discussed how the information could be used in terms of an actual decision. The right side of figure 4 represents the potential outcomes and values associated with having the data and the counterfactual if the data are not available. The group discussed the need for information for a public health alert system. If the information is not precise, it is possible (with some unquantified probability) that alerts will occur too frequently. This will lead to unnecessary sheltering and associated costs. It is also possible that with many unneeded warnings, people may become less responsive to warnings and that could in turn result in health effects. On the contrary, not enough information could lead to an alert system that does not provide warnings when it should. This has risks associated with human-health effects and the associated costs. Perfect information would support optimization of the alert system and that would balance the risk to human health with the costs associated with sheltering. The breakout group also began another branch on the decision tree (right side) of the value chain for which they considered applying the information in a traffic management system. In that case, perfect information would support optimization of traffic controls to reduce emissions during high-heat events leading to reduced human-health effects. The counterfactual (without information) was not developed during the session. The preliminary value chain/decision tree helps to consider how weather and temperature information could be used to reduce human-health effects, who the users might be, and the value of collecting and analyzing additional information.

\section{Group 2-Flooding-Mitigating. Managing, and Avoiding Impacts to Safety and Property Damage}

The second group included hydrologists, economists, and engineers (table 2). They addressed the flood issue with a specific focus on Hurricane Matthew, which resulted in inland and coastal impacts. They worked backwards, asking who the actors are and what decisions and processes should be resolved. There were several phases to consider: pre-event planning and preparedness, response activities, recovery phase, and economic impacts. After approaching the flood issue at a high level, they went into detail to select a single thread, isolating one actor and one decision-focusing on a dam operator.

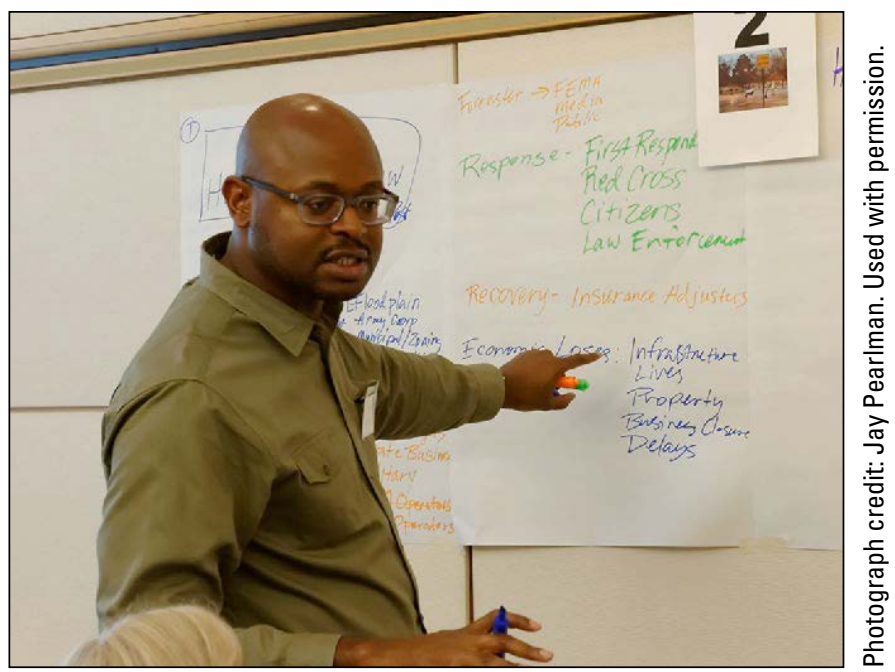

Table 2. Group 2 participants.

\begin{tabular}{ll}
\hline \multicolumn{1}{c}{ Name } & \multicolumn{1}{c}{ Organization } \\
\hline DaNa Carlis ${ }^{1}$ & $\begin{array}{c}\text { National Oceanic and Atmospheric } \\
\text { Administration. }\end{array}$ \\
Nancy Colleton & $\begin{array}{c}\text { Institute for Global Environmental } \\
\text { Strategies. }\end{array}$ \\
Andrew Coote & ConsultingWhere Ltd. \\
Pat Cummens & Esri. \\
Jason Gallo & Science and Technology Policy Institute. \\
Monica Grasso & National Oceanic and Atmospheric \\
& Administration. \\
Robert Mason & U.S. Geological Survey. \\
Francoise Pearlman & FourBridges. \\
Tim Stryker & U.S. Geological Survey. \\
Toste Tanhua & Global Ocean Observing System. \\
\hline
\end{tabular}

${ }^{1}$ Facilitator.
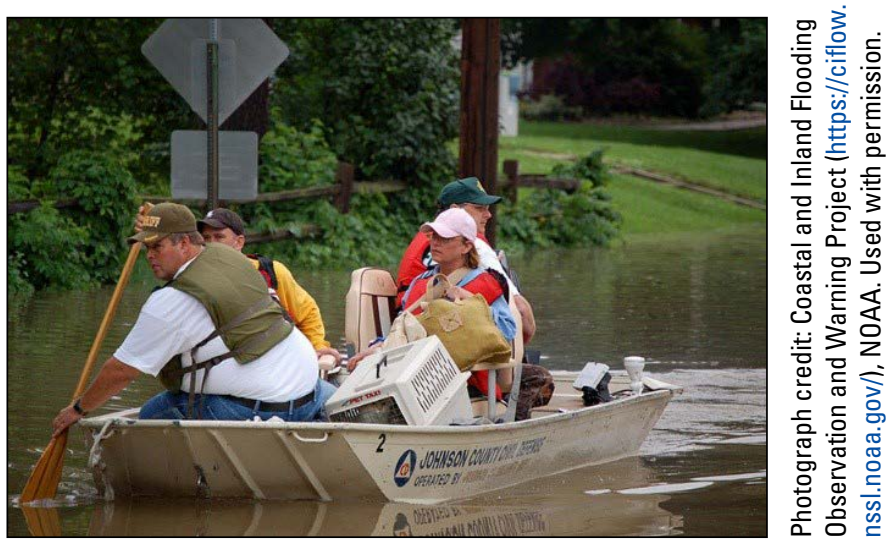

Residents being evacuated from high flood waters. 


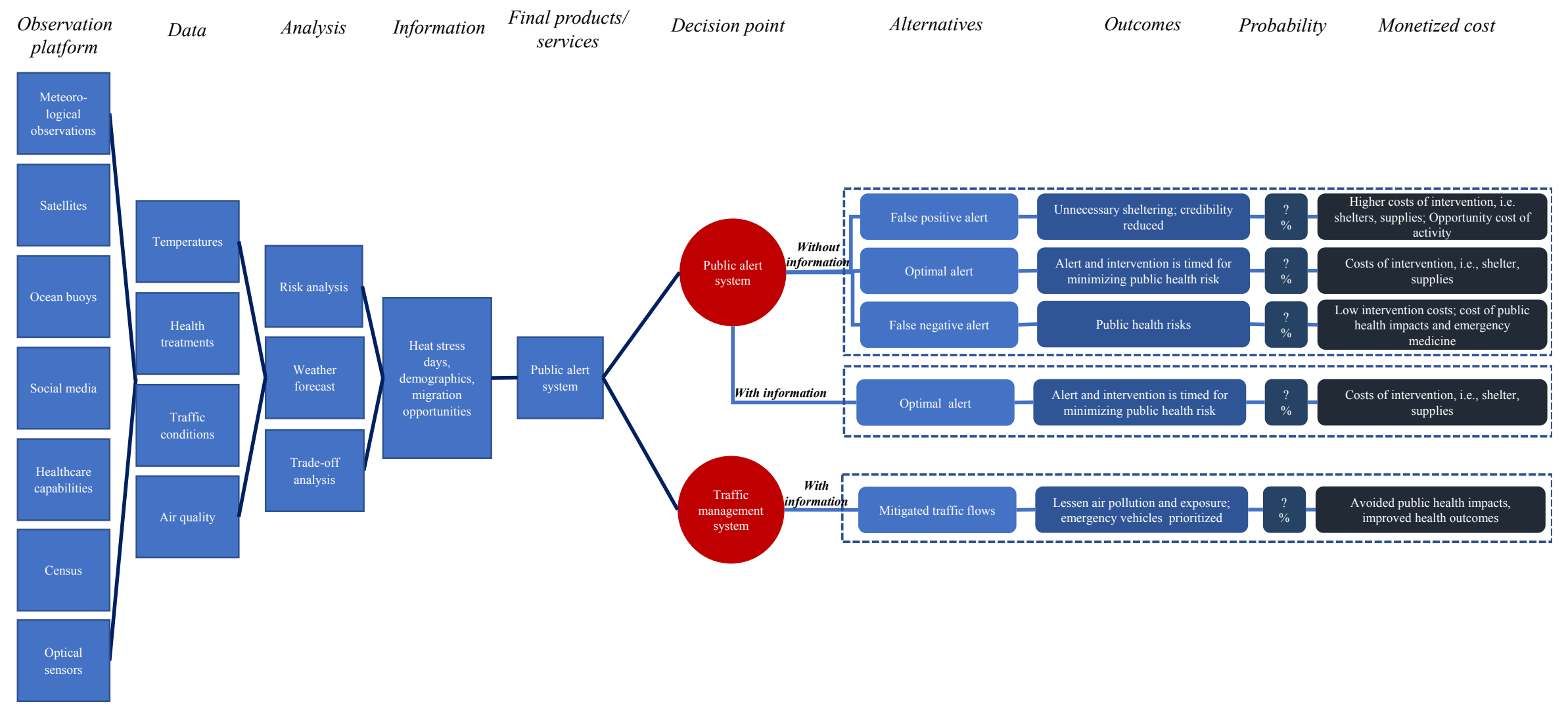

Figure 4. Effects of increasing temperatures on human-health value chain/decision tree. 
Looking at the supply chain, group 2 considered the decisions being made (which include when to release water from the dam, how much to release, and for what duration), what information the dam operator needed to make a decision (hydrology, upstream data, downstream data, and reservoir), and the systems providing the information (platforms, sensors, and decision-support systems).

The group identified several challenges in determining the VOI for this application:

- There are multiple criteria to be applied regarding multiple decisions or parts of decisions that eventually need to be merged.

- The situation is highly complex.

- There is a need for a wide variety of expertise.

- There is a risk of double counting.

- Federal dam operators have a Federal plan to comply with, leading to interplay between policy and decisions.

A question that arose during this discussion included looking at a complexity and authority chain - who is making decisions and where? Also, how is the decision modified by information sharing and communication? The decision tree developed by the group (fig. 5) included three branches: one for a decision on dam release, a second for emergency management response, and a third for flood-plain management. The dam release branch was the most developed. The group identified the counterfactual scenario (without information) and the possibilities that there could be too much water released associated with flooding downstream or too little water released leading to damage to the dam itself. With perfect information, the release of water could be optimized to balance all the risks and associated costs.

\section{Group 3-Harmful Algal Blooms-Effects on Human Health, Recreation, and Tourism}

The third group focused on an early warning forecast for HABs. The forecast incorporates upstream models, which use in-situ and satellite data, some of which were produced for other purposes. The group considered the information product users and the beneficiaries, which include drinking water producers, aquaculture operators, wild fisheries, municipalities, charter boat operators, and recreationists. Participants included hydrologists, economists, and data managers with expertise in HABs (table 3).

Table 3. Group 3 participants.

\begin{tabular}{ll}
\hline \multicolumn{1}{c}{ Name } & \multicolumn{1}{c}{ Organization } \\
\hline Jim Boyd & $\begin{array}{l}\text { National Socio-Environmental Synthesis } \\
\text { Center, Resources for the Future. }\end{array}$ \\
Max Craglia & $\begin{array}{l}\text { European Commission, Joint Research } \\
\text { Centre. }\end{array}$ \\
Jennifer Graham & U.S. Geological Survey. \\
Yusuke Kuwayama & $\begin{array}{l}\text { Resources for the Future. } \\
\text { Doug Lipton }\end{array}$ \\
& $\begin{array}{l}\text { National Oceanic and Atmospheric } \\
\text { Administration. }\end{array}$ \\
Lou Nadeau & Cooperative Research Centre for Spatial \\
Michael Ott & Information. \\
& Intergovernmental Oceanographic \\
Emily Pindilli & Commission. \\
Theodore Stawecki & U.S. Geological Survey. \\
Steven Thur & LimnoTech. \\
& National Oceanic and Atmospheric \\
\end{tabular}

${ }^{1}$ Facilitator.

${ }^{2}$ Rapporteur.

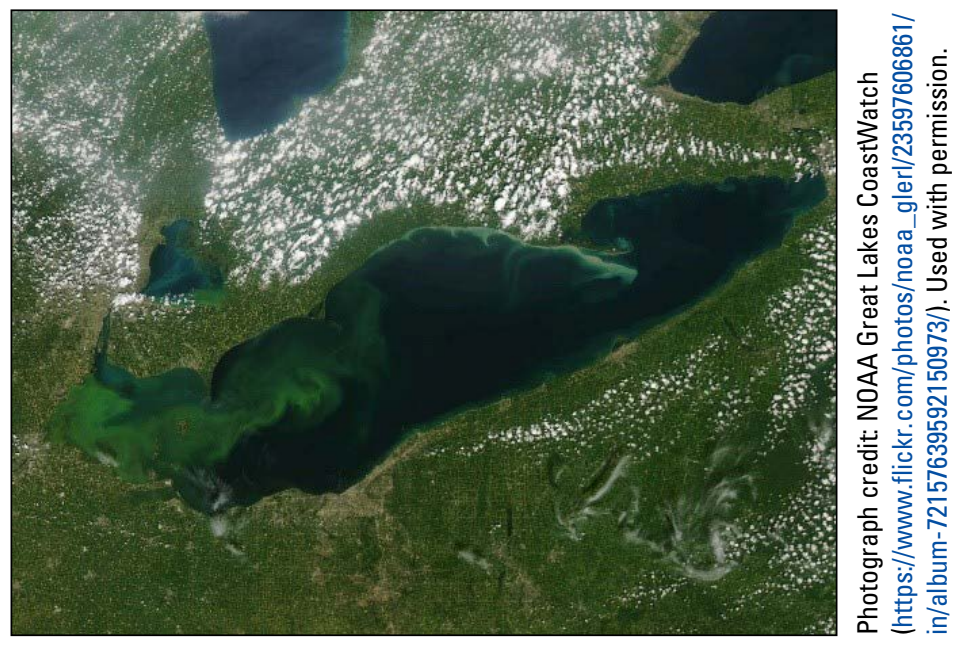

MODIS (aqua) satellite image of Lake Erie harmful algal bloom, August 22, 2015. 


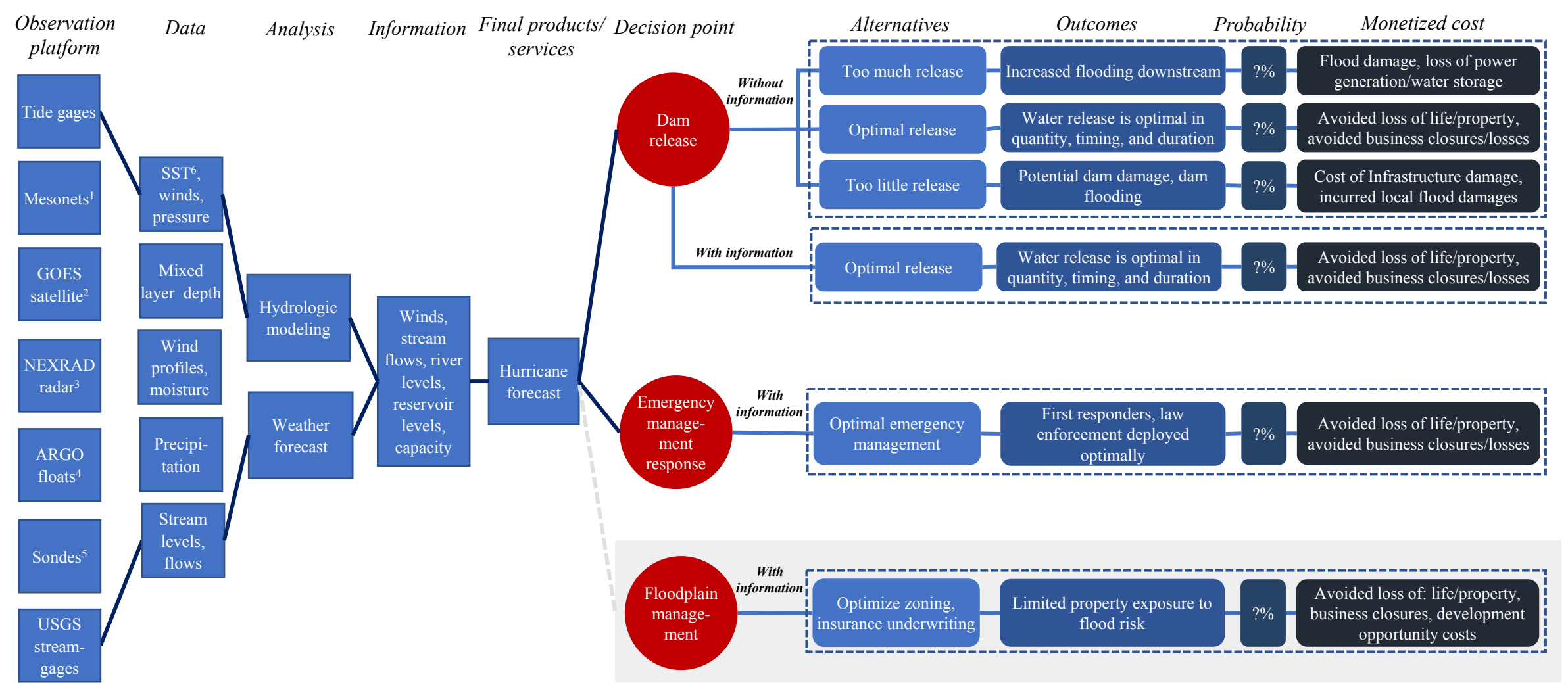

Definitions: 1. A network of automated weather and environmental monitoring stations that observe mesoscale meteorological phenomena; 2. National Oceanic and Atmospheric Administration's Geostationary Operational

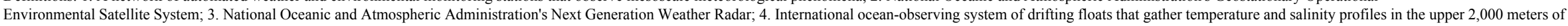
the world's oceans. 5. Multi-parameter water monitoring svstems: 6 . SST = sea surface temperature.

Figure 5. Flooding: Mitigating, managing, and avoiding impacts to safety and property damage value chain/decision tree. 


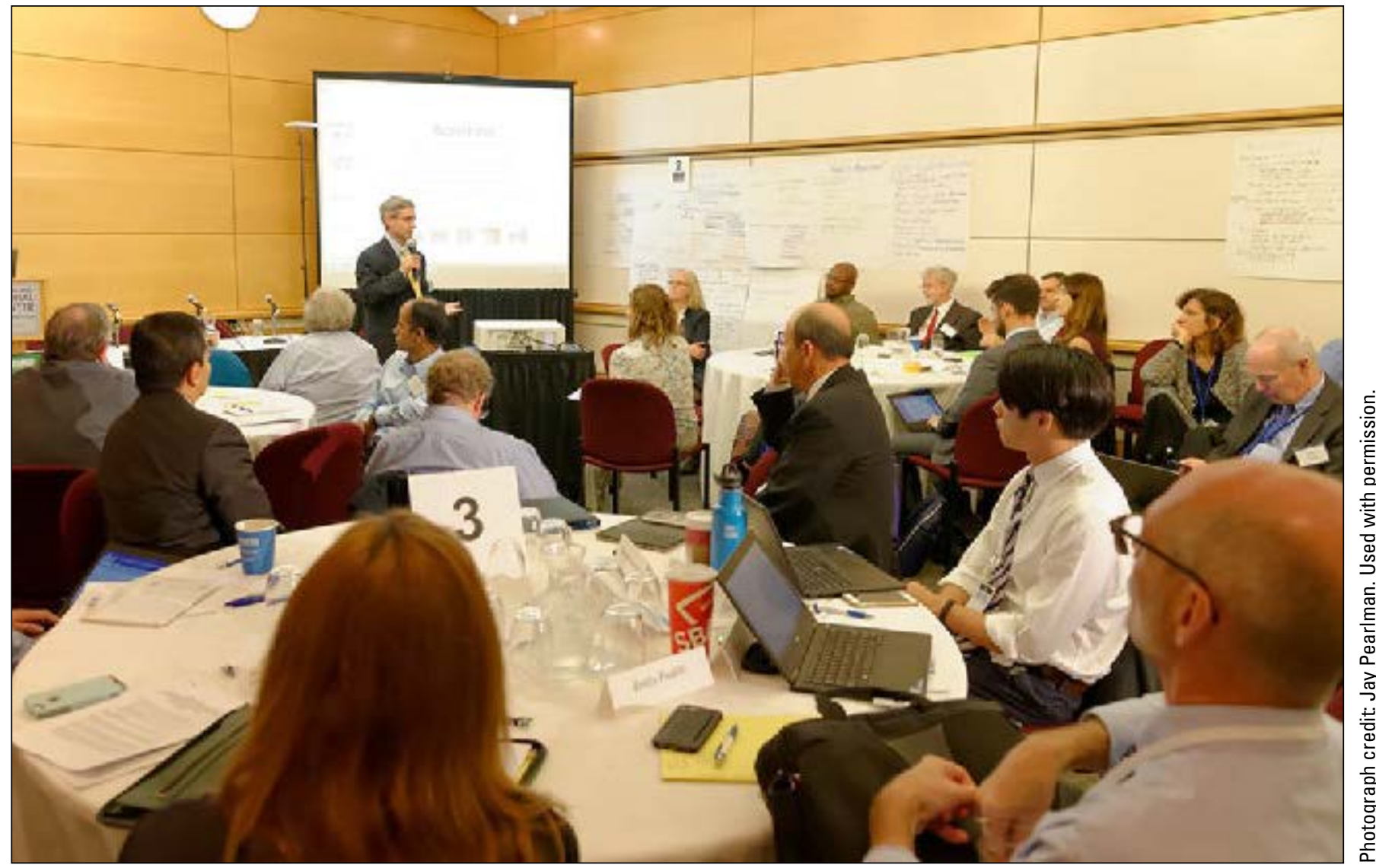

During the discussion, participants considered the longevity of the VOI if the goal is to avoid HABs; eventually we will not benefit from early warning systems. Participants also discussed if public confidence in the government and information could be accounted for.

The value chain/decision tree that the group developed is shown in figure 6 . The final information product that was used to consider the decision-tree branches was an early warning system that relies on satellite imagery, in-situ observations, and additional analytic capabilities. Five different branches were considered with drinking-water management being the most developed. In the case of drinking-water management, participants identified the different decision paths that might occur without information. It is possible that there could be too much treatment (that is, too many chemicals or starting treatment before needing to) or too little treatment. In the case of too much treatment, there are costs associated with the treatment itself and potentially alternative sources of water (such as bottled water). If there is too little treatment, there are human-health risks including gastrointestinal illness and amnesia; there are also less well understood long-term health risks. For this application, perfect application can support the optimization of balancing intervention costs with humanhealth risks. The value of cyanobacteria HABs science is currently being researched at the USGS to better understand users, priority information, and benefits of the science.

\section{Group 4-Energy and Mineral Supply- Mitigating, Managing, and Avoiding Impacts of Shortfalls on the Economy}

EO data can be used at different stages of energy and mineral supply management: from exploration to planning and from monitoring to environmental impact assessments. The fourth group narrowed the scope of its topic to the siting of wind farms. Group 4 participants included energy economists, geologists, and engineers (table 4). Potential users of information include investors, regulators, citizens, energy producers, and energy users. The information needed includes data on weather, climate, and terrain, which leads to mapping products. Critical analysis for wind-farm siting includes cadaster (that is, property) and terrain analysis to better understand the landscape including human dimensions where a wind farm may be placed. During the discussion, participants considered whether the value chain/decision tree should be developed from the perspective of project planning or project operations. The participants also considered political will and societal willingness to accept wind farms in one's community and the influence that these factors have on the decision-making process. 


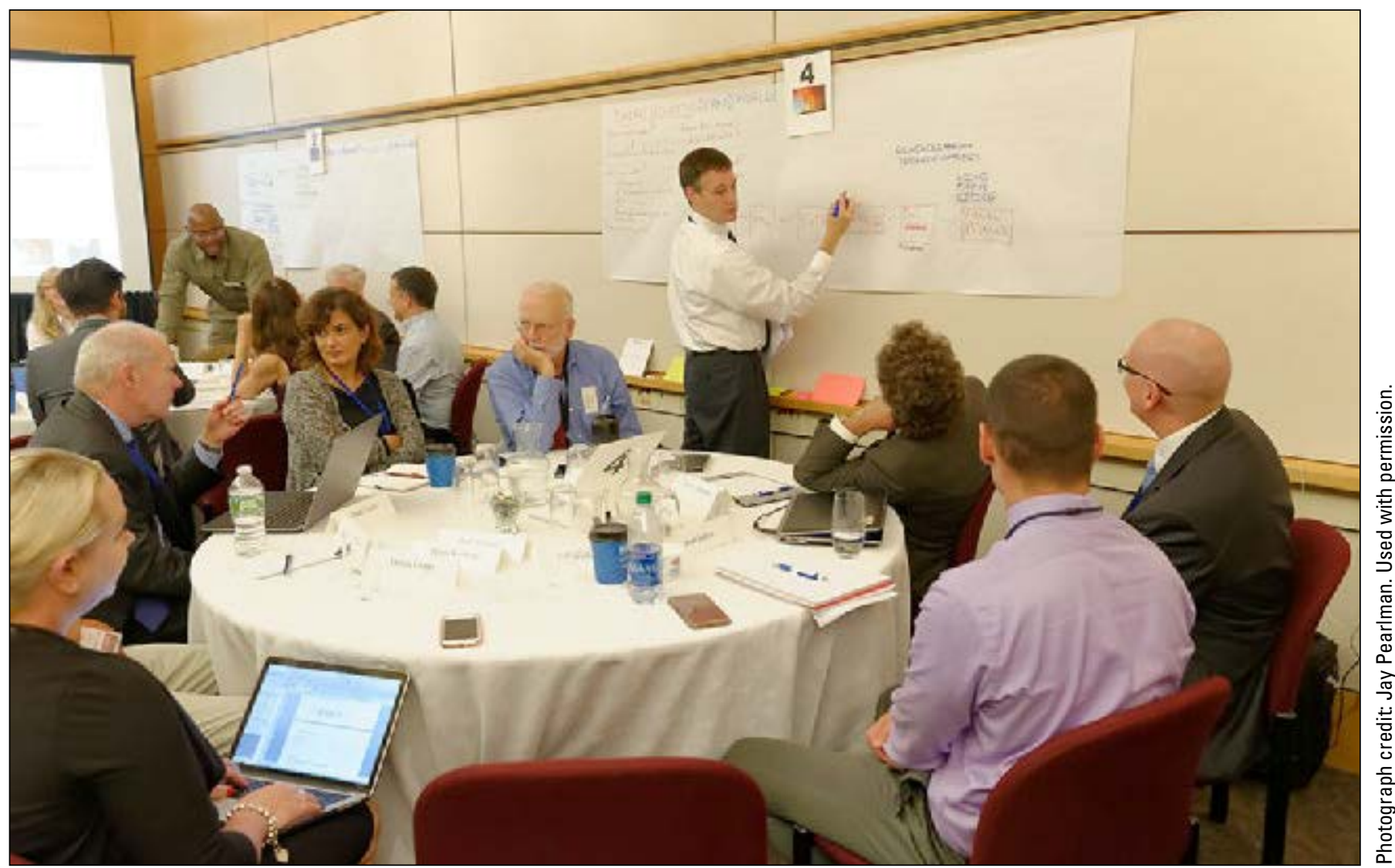

Table 4. Group 4 participants.

\begin{tabular}{ll}
\hline \multicolumn{1}{c}{ Name } & \multicolumn{1}{c}{ Organization } \\
\hline $\begin{array}{l}\text { Steven Anderson } \\
\text { Tom Crafford }\end{array}$ & U.S. Geological Survey. \\
Denna Geppi ${ }^{1}$ & U.S. Geological Survey. \\
& Aational Oceanic and Atmospheric \\
Josh Jankot & National Oceanic and Atmospheric \\
& Administration. \\
Graeme Kermich & Cooperative Research Centre for Spatial \\
& Information. \\
Haris Kontoes & University of Athens. \\
Lef Mamais & Evenflow Consulting. \\
Larry Meinert & U.S. Geological Survey. \\
Kevin Schrab & National Oceanic and Atmospheric \\
& Administration. \\
Alessandra Tassa & European Space Agency. \\
Jeff Williams & \\
& National Oceanic and Atmospheric \\
\end{tabular}

${ }^{1}$ Rapporteur.

${ }^{2}$ Facilitator.
A representative value chain/decision tree based on the group's discussion is shown in figure 7 . The application, windfarm siting, potentially relies on several different types of satellite imagery. Meteorology, wind climatology, off-shore near surface wind fields, and terrain all feed into analysis of the wind capacity in an area. The group discussed the importance of overlaying this information with property cadaster and other sociopolitical constraints to inform siting in areas that have high wind-energy capacity, and are not disruptive to existing housing developments, do not intersect with environmentally sensitive areas, or both.

The decision-tree component of the value chain focused on the benefit of the information for informing optimal wind-farm siting. In the counterfactual, it is possible that a wind farm is sited in an area that is ultimately not feasible for development based on either societal constraints of environmental sensitivities. Although this may be a high wind-energy capacity area, a decision to pursue siting in that area without relevant information would likely lead to wasted infrastructure and administrative costs. On the other branch of the counterfactual, there may not be any barriers to wind farm development; however, the area may not be ideal for wind energy generation. This could lead to reduced energy generation, foregone revenues, and lower return on investment. 


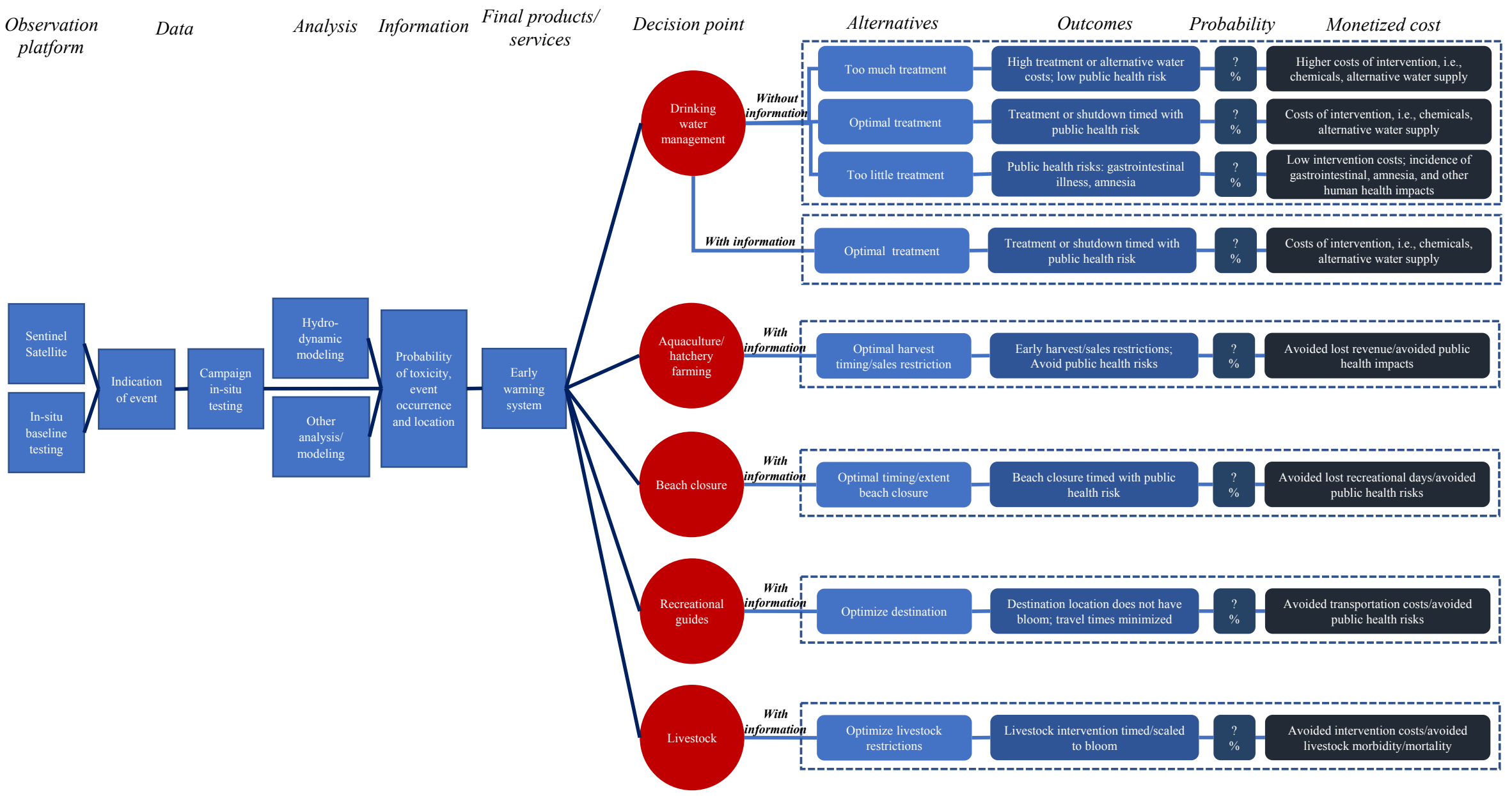

Figure 6. Harmful algal blooms (HAB): Effects on human health, recreation, and tourism value chain/decision tree. 


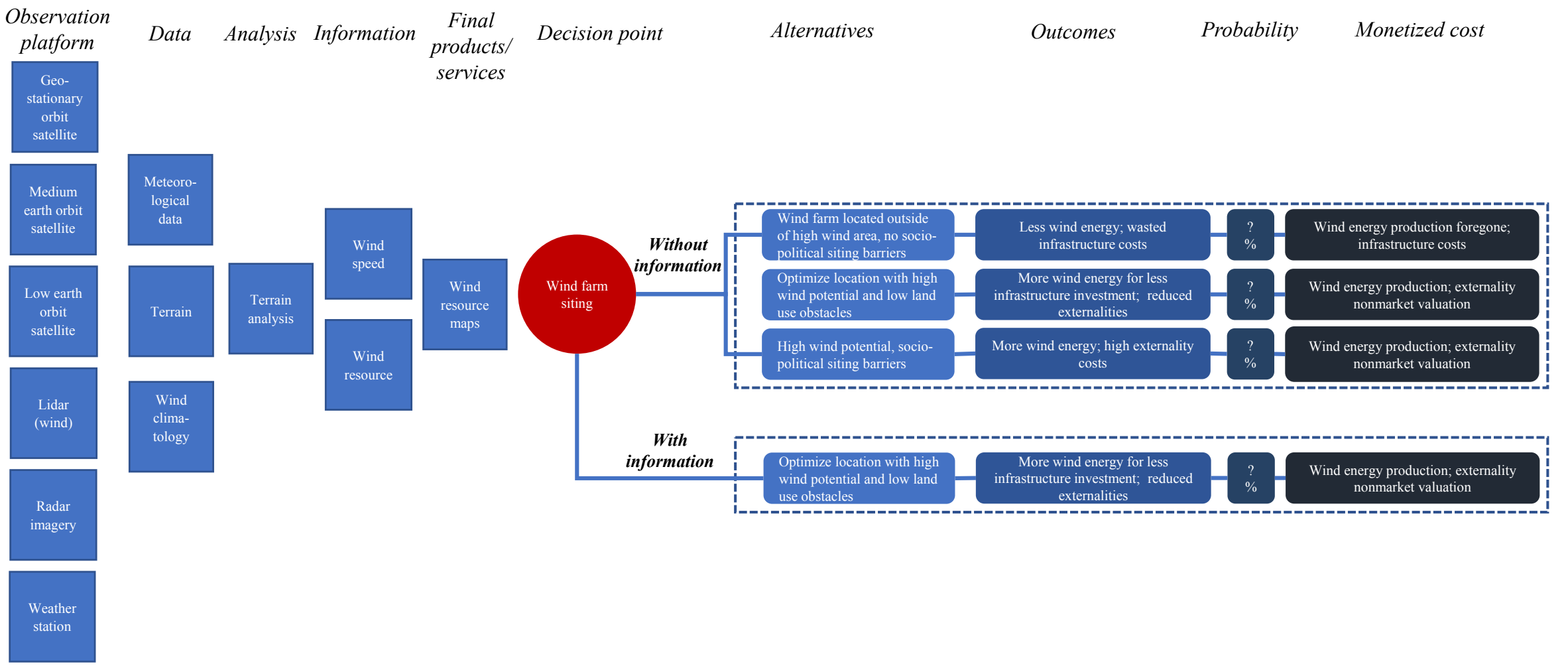

Figure 7. Energy and mineral supply: Mitigating, managing, and avoiding impacts of shortfalls on the economy value chain/decision tree. 


\section{Group 5-Effects of Natural Hazards on Transportation Systems-Effects on Mobility, Safety, and the Economy}

The fifth group looked at the impact of ash from volcanic eruptions on transportation (especially air traffic). Participants included a volcanologist, economists, and engineers (table 5). The major user of information is the Federal Aviation Administration (FAA), which decides whether or not flight routes are modified or cancelled. The information needed for this application includes ash cloud forecasts and metrics associated with air traffic, which may be derived from satellite and ground instrumentation. The group considered the commercial case, DHL a cargo handler, as the beneficiary of the decision.

The value chain/decision tree for the effects of a volcano eruption on the transportation system is shown in figure 8 . Observations from satellite and doppler radar provide data on sulfur dioxide cloud location, density, and direction. Together with weather and ash models, this ultimately provides an ash forecast. This information may be used by many transportation managers; the group focused on decisions made by the FAA on whether or not to modify flights with an example benefactor of DHL, a commercial cargo carrier. In the counterfactual scenario, without information, there is a chance that the FAA would ground or divert air traffic too often with associated costs of fuel and lost time. Alternatively, the FAA may not
Table $5 . \quad$ Group 5 participants.

\begin{tabular}{ll}
\hline \multicolumn{1}{c}{ Name } & \multicolumn{1}{c}{ Organization } \\
\hline Jeffery Adkins & $\begin{array}{c}\text { National Oceanic and Atmospheric } \\
\text { Administration. }\end{array}$ \\
Aanchal Anand & World Bank. \\
Victoria Avery $^{1}$ & U.S. Geological Survey. \\
Christopher Katalinas $^{2}$ & National Oceanic and Atmospheric \\
& Administration. \\
Jamie Kruse & East Carolina University. \\
Jay Pearlman & FourBridges. \\
Steven Ramage & Group on Earth Observations \\
& Secretariat. \\
Carl Shapiro & U.S. Geological Survey. \\
Alan Smart & ACIL Allen Consulting. \\
\hline
\end{tabular}

${ }^{1}$ Rapporteur.

${ }^{2}$ Facilitator.

ground or divert traffic soon enough. This could have safety impacts, costs associated with equipment damage or loss, or both. There are many additional uses of ash cloud maps that could be considered when estimating the value of this information.

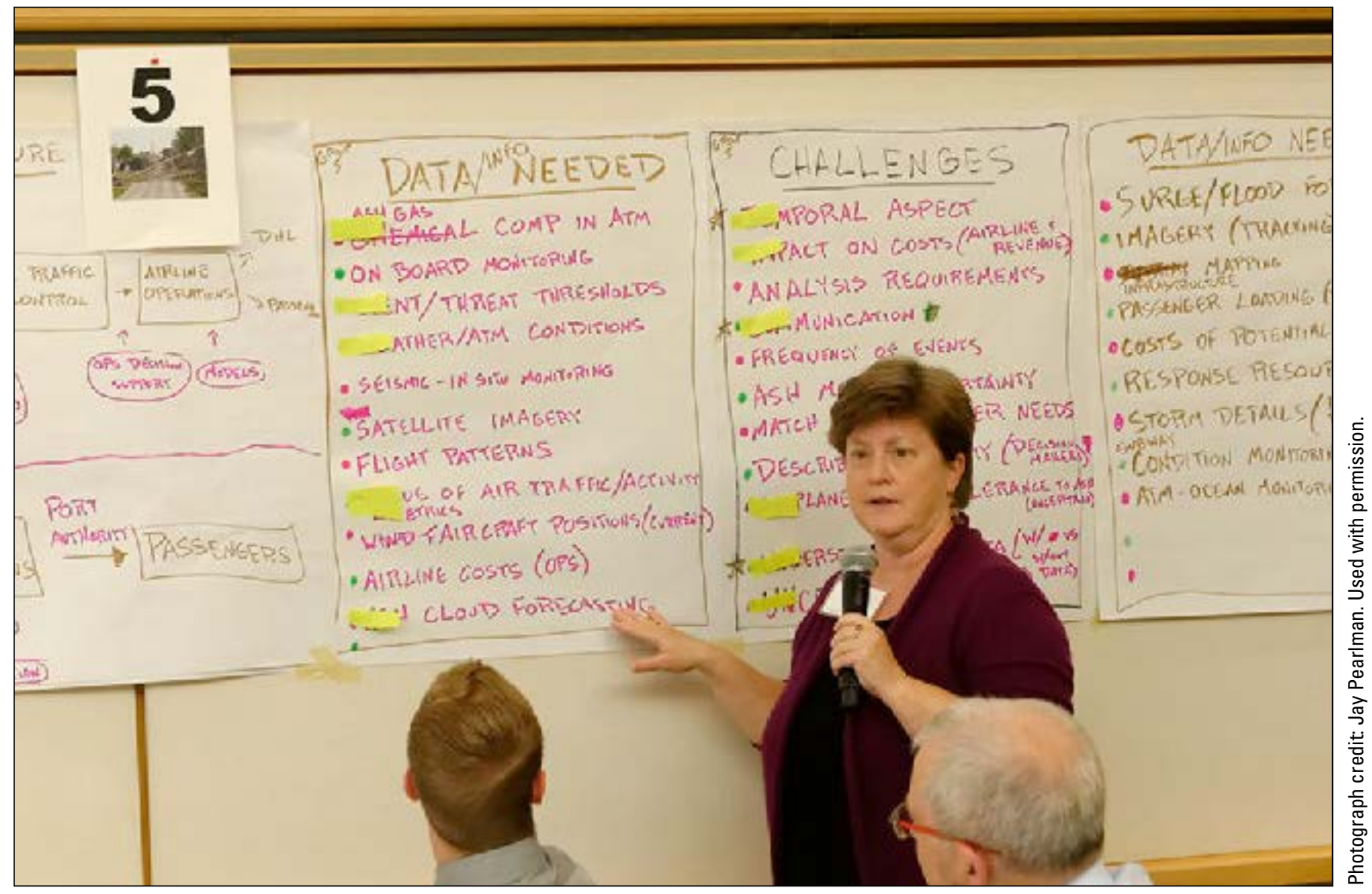




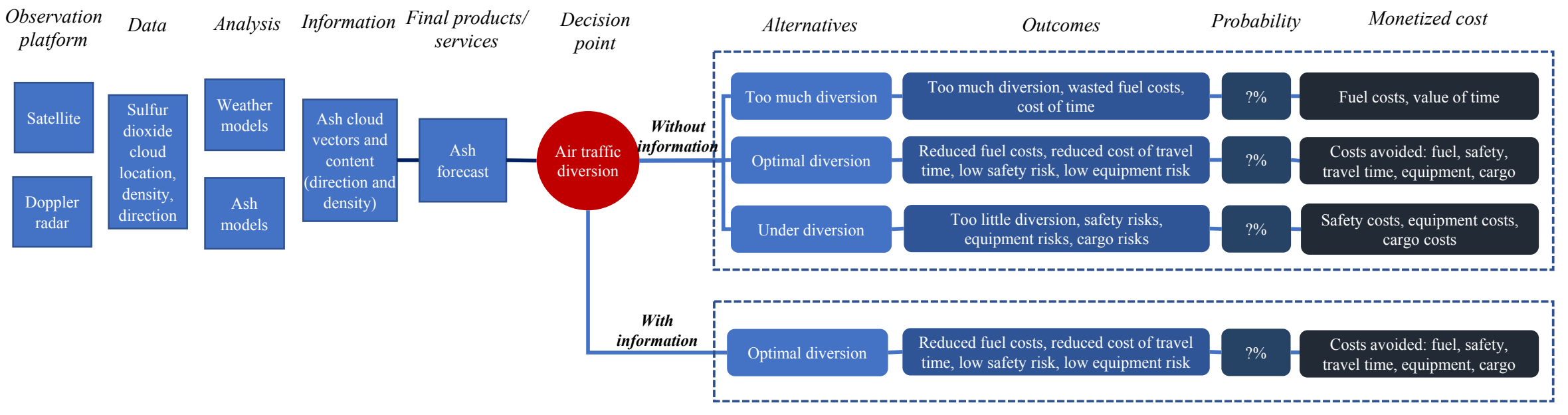

Figure 8. Effects of natural hazards on transportation systems: Effects on mobility, safety, and economy value chain/decision tree. 


\section{Open Discussion-Working Group Approaches to Developing Value Chains and Decision Trees}

After the breakout group discussions and report out, the full group reconvened to discuss value-chain/decision-tree development and the approach identified by each working group. Workshop participants discussed the value in addressing actual systems that exist now (such as the National Water Model) instead of hypothetical situations. Jay Pearlman mentioned the use of historical use cases, such as the eruption in Iceland and Hurricane Sandy. Alan Smart discussed the importance of attribution to a specific input and incremental improvements. Victoria Avery and Rich Bernknopf discussed the value of recasting a historical event in current or future contexts.

Andy Coote stated that it is great if you can go back and look at data; however, in the developing world, those data are not always available. Also, Andy mentioned how value chains/ decision trees are often described as linear but, in fact, are networks. A lot of information is lost in analyzing networks as linear processes. Participants also discussed how value chains/ decision trees are based on existing products. Carl Shapiro discussed ex-ante and ex-post analyses and how this information going forward can create societal benefits. For this to occur, it is critical to do a retrospective analysis to anchor the value chain/decision tree in reality.

Regarding the need for public engagement, Pierre Glynn mentioned how thinking about the value chain/decision tree can help create opportunities for participatory planning and public understanding. Another participant discussed how the climate resilience toolkit can document how communities prepare themselves and how its use can help to promulgate solutions. Value chains/decision trees can be used as a communication tool to demonstrate the value of this tool kit. Lastly, another participant mentioned using the value of loss of life as a means of assessing tradeoffs faced by the airline industry in dealing with volcanic ash (as one constraint to its decision).

\section{Synthesis, Findings, and Next Steps}

\section{Synthesis}

This workshop was organized in three distinct parts: an overview of methodologies to value EO, a focus on the use of value chain and decision-tree frameworks, and the application of these frameworks for several predetermined applications. During the first part, a series of briefings was provided to examine different approaches to estimating the value of EO. The latest methods were discussed. The presentations included a number of case studies and applications. One approach to estimating the VOI is to derive users' willingness to pay either via revealed preference (that is, market prices) or stated preference (such as choice experiments). An example of this approach is the estimation of the value of Landsat moderate resolution data, which used a survey technique (Miller and others, 2011), and a second example can be found in Europe, where work has focused on the value of the data coming from Copernicus Sentinel satellites.

Three use-case studies have been completed based on a product value-chain methodology. Reports and a video are available through EARSC (https://earsc-portal.eu/pages/ viewpage.action?pageId=35620366). A similar approach was also used to consider a specific application of information to estimate the value of the NASA GRACE for enhanced drought severity index. In this case, researchers determined that adding GRACE indicators reduced the number of prediction errors in the larger dollar value ranges accruing cost savings (Bernknopf and others, 2017). Each approach has benefits and drawbacks. Approaches that look at national-scale or economic-wide impacts may be most appropriate when needing to estimate the total economic value of EO; however, it does not always provide a clear narrative of the use and benefits of information. Focusing on a single application too has constraints. Estimating the value of a single use may not provide a good indicator of the full VOI. Another common issue with all approaches is being able to discern the value of any component of EO and its contribution to benefits.

A framework that can help overcome some of the limitations of other approaches is the value-chain/decision-tree framework. During the workshop, the traditional value chain derived from business models was discussed. The purpose of the supply of information value-chain delineation supports an understanding of the share of contribution from each type of data in the flow to the information and to the benefits. Importantly, in addition to the traditional value chain, the addition of a decision tree was discussed as a way to understand the qualitative relationship between information and decisions. The actual monetization of benefits could take many different forms, including market, nonmarket, revealed preference, and stated preference approaches. The uniting theme is the framework that puts EO into the context of the user and the decisions being made that the information supports.

\section{Findings}

Finding 1: It is critical that improved understanding of the value of EO be developed.-This understanding is important to science and policy. Policymakers and scientists benefit from an understanding of the value of EO to improve development and use of EO and to effectively capitalize on key opportunities. Managers and policymakers need this understanding so that informed decisions and priorities can be developed to use scarce resources or make new investments most effectively. Industry can use the information to promote the benefits of the technology and hence its capabilities.

Finding 2: The understanding of the value of $E O$ is facilitated by a description or narrative clearly explaining the basis for societal benefits from $E O$ and a quantified estimate of the value in monetary or nonmonetary terms.-The narrative and 
the quantification are important components of an understanding of the value of EO. The narrative provides the intuition or description of how benefits are created and the quantification provides a measure of the magnitude or size of the benefits. Together they develop an understanding of the value of EO.

Finding 3: Narratives that explain the basis of the societal benefits from the use of EO need to provide a clear and relatively simple explanation of how $E O$ can create an improved societal outcome.-With a multidisciplinary team that integrates the knowledge base of economists, physical and biological scientists, decision scientists, and science communicators, narratives of societal benefits can be addressed comprehensively in a short time if the concept remains clear and simple. A common language and set of concepts is also critical for the advancement of the value of EO.

Finding 4: Value chains and decision trees can be useful tools in understanding the value of EO.-It is important to extend the value chain concept beyond the development of an information product from EO and to consider how the information product impacts societal decisions. As a result, value chains can be useful in describing the process of producing information products from EO, as well as illustrating how an information product impacts a societal decision. A counterfactual can be obtained by considering the approach that was used before information became available. It is important when considering a counterfactual scenario that other factors that may influence the decision are held constant or otherwise incorporated into the analysis. Value chains and decision trees provide an analytical framework for evaluating the impact of EO in decision making and clearly describe what happens with and without the knowledge gained from the EO.

Finding 5: Use cases help advance the state of the science of valuing information. - Use cases provide clear examples of how EO information is used by a specific set of stakeholders for a specific use. By narrowing down several uses or decisions that EO could be used for, a use case allows for detailed analysis of the VOI for that purpose.

Finding 6: Innovations in quantifying the value of information are needed.-Currently, valuing EO is done largely on an ad-hoc basis and requires a lot of time and resources to conduct. Innovations in the types of data used, ways that data are collected, or both could create efficiencies so that EO could more readily be evaluated.

Finding 7: GEO provides an institutional pathway for engaging an international community for the research and application of valuing EO.-GEO has 105 member countries and 127 participating organizations and has been considering the use of EO for more than a decade. GEO's international membership provides expertise in EO along with interested stakeholders that make it a great connection for the small community that is actively engaged in valuing EO. It would be useful to strengthen the linkage with GEO to increase visibility and leverage expertise.

\section{Next Steps}

The workshop was successful in highlighting and understanding value chains and decision trees relating to EO. Participants provided important input on developing five initial value chains/decision trees. There was support for the ongoing role of the GEOValue Community and for organizing meetings in varying locations to extend the GEOValue Community to other nations and most importantly to promote the key messages. The European Space Agency offered to host a next meeting in 12 to 18 months (late 2018 or early 2019). The value chains/decision trees developed in the workshop will continue to be worked with different subsets of groups. The next GEOValue Community meeting is expected to further consider this methodology and tackle other common issues with valuing EO.

Research on understanding and quantifying the value of EO is advancing, but additional progress is still needed. The following future directions will enhance efforts to develop improved understanding of the value of EO.

1. Innovative approaches need to be discovered and leveraged.-The process of developing value chains is key for the understanding of all potential benefits of EO but can be very costly and time consuming. The EO community needs to leverage and foster innovations to strengthen its ability to develop these complex and important value chains. For example, the use of a platform to develop a crowdsourced value chain where all experts and users have access, can provide their input, and can get feedback.

2. The GEOValue Community needs to continue and be strengthened.-Assessing the VOI is a broad challenge that affects diverse disciplines and organizations around the world. The GEOValue Community provides structure and organization for sharing best practices, opportunities, and challenges in efforts to understand and communicate the value of EO. It provides an international perspective across multiple disciplines and experiences. Linking with GEO can be a useful way to extend the international reach of GEOValue. The GEOValue community should continue to convene workshops and other meetings to facilitate information sharing and collaboration across its broad set of stakeholders.

3. Further case studies should be developed to cover as wide a range as possible of thematic, product, and geographical dimensions. - EO derived information covers many thematic areas and is applicable to many market sectors. It is also global in dimension. As wide a coverage as possible should be encouraged to provide comparisons and complementary case results. 
4. The different methodologies should continue to be developed and compared exploring the viability, effectiveness, and best practices for the use of value chains and decision trees in analyzing the value of EO.-There seems to be great potential in the use of this approach in understanding and in communicating the benefits from the use of EO. The development of case studies across different organizations in different contexts and policy situations can provide additional understanding of the usefulness and best implementation practices for the effective use of value chains and decision trees.

5. Practical illustrations of value-chain applications through results from case studies should be shared and discussed at a future GEOValue workshop.-It is noted that much progress was made in understanding the value of EO for five examples in short breakout sessions with experts from different disciplines and organizations. With the development of case studies focusing on the use of this method, there is great potential for more effectively enhancing the use of value chains and decision trees to advance understanding, quantification, and communication of the value of EO. Some of the examples, such as toxic HABs are being used as a framework to further study the benefits of information by the USGS.

6. The international, interdisciplinary dimensions should continue to be developed to draw out the richness of case analyses.-Environmental satellites create value for society through value chains that include instrument design and deployment, data collection and management, research and analysis, and the production of final products that inform decisions across a wide range of economic sectors and government agencies. The data collected by a global system of environmental satellites are not constrained by political boundaries and are, thus, international in nature and utility. Case studies must reflect the contributions of the full range of disciplines involved in creating societal value with data collected by environmental satellites, including the engineers who design and deploy instruments, the full spectrum of scientists required to use these data to create useful products, and the operational staff in industry and government who use these products. Benefit assessments, which more commonly focus on the benefits to a nation or other political entity, should be broadened to include or at least acknowledge the international and sometimes global scope of societal benefits.

\section{References Cited}

Adams, R.M., Bryant, K.J., Mccarl, B.A., Legler, D.M., O'Brien, J., Solow, A., and Weiher, R., 1995, Value of improved long-range weather information: Contemporary Economic Policy, v. 13, no. 3, p. 10-19. [Also available at https://doi.org/10.1111/j.1465-7287.1995.tb00720.x.]

Adkins, J., 2017, Economic valuation of NOAA products \& services: GEOValue side event workshop, Washington, D.C., October 23-24, 2017, accessed July 28, 2017, at http://www.geovalue.org/wp-content/uploads/2018/04/ adkins.pptx.pdf.

Anand, A., and Kelm, K., 2016, The economic value of geospatial information-An Albania case study: 17th Annual World Bank Land and Poverty Conference, Washington, D.C., March 14-16, 2016. [Also available at https://slideplayer.com/slide/10573529/.]

ACIL Allen Consulting, 2015, The value of Earth observations from space to Australia: ACIL Allen Consulting, report to the Cooperative Research Centre for Spatial Information, 105 p., accessed May 2, 2018, at http://www.crcsi.com.au/ assets/Program-2/The-Value-of-Earth-Observations-fromSpace-to-Australia-ACIL-Allen-FINAL-20151207.pdf.

Babcock, B.A., 1990, The value of weather information in market equilibrium: American Journal of Agricultural Economics, v. 72, no. 1, p. 63-72. [Also available at https://doi.org/10.2307/1243145.]

Bernknopf, R., Kuwayama, Y., Brookshire, D., Zaitchik, B., Thompson, A., Vail, P., and Macauley, M., 2017, A decision framework for quantifying the economic value of information (VOI) of EO - Case for a NASA Gravity Recovery and Climate Experiment (GRACE) enhanced drought severity index: GEOValue side event workshop, Washington, D.C., October 23-24, 2017, accessed July 28, 2017 , at http://www.geovalue.org/wp-content/uploads/2018/04/ Bernknopf.pptx.pdf.

Coote, A., 2017, Value chain and cost-benefit analysisApplied to 3D geo-information: GEOValue side event workshop, Washington, D.C., October 23-24, 2017, accessed July 28, 2017, at http://www.geovalue.org/ wp-content/uploads/2018/04/coote.pptx.pdf.

Cummens, P., and Kinn, G., 2017, Esri perspective: GEOValue side event workshop, Washington, D.C., October 23-24, 2017, accessed July 28, 2017, at http:/www.geovalue.org/ wp-content/uploads/2018/04/pat-cummens.pptx.pdf. 
Group on Earth Observations, 2017a, Demonstrating the value of earth observations-Methods, practical applications and solutions: Group on Earth Observations video, 05:46:54, posted November 7, 2017, accessed July 28, 2017, at https://www.youtube.com/watch?v=kX9mALevn2I\&index= 4\&list=PLCOcU8-SEsU0v4Gc_sGcLQhdytIFBBnts.

Group on Earth Observations, 2017b, Demonstrating the value of earth observations-Methods, practical applications and solutions: Group on Earth Observations video, 02:33:46, posted November 7, 2017, accessed July 28, 2017, at https://www.youtube.com/watch?v=k8iG3LbD$1 w \&$ feature $=$ youtu.be $\& \mathrm{t}=8 \mathrm{~s}$.

Group on Earth Observations, 2017c, GEO week 2017: Group on Earth Observations video playlist, posted November 14, 2017, accessed July 28, 2017, at https://www.youtube.com/ playlist?list=PLCOcU8-SEsU0v4Gc_sGcLQhdytIFBBnts.

Hallegatte, S., 2017, Simple assessments of the benefits from early warning systems and stronger hydro-meteorological system: GEOValue side event workshop, Washington, D.C., October 23-24, 2017, accessed July 28, 2017, at http://www.geovalue.org/wp-content/uploads/2018/04/ Hallegatte-Value-of-weather-services.ppt.pdf.

Hersh, R., and Wernstedt, K., 2002, Gauging the vulnerability of local water utilities to extreme events: Journal of Environmental Planning and Management, v. 45, no. 3, p. 341-361. [Also available at https://doi.org/10.1080/09640560220133397.]

Johnson, S.R., and Holt, M.T., 1986, The value of climate information: Iowa State University, Center for Agricultural and Rural Development Staff Report 86-SR6. [Also available at http://lib.dr.iastate.edu/card_staffreports/79.]

Kuwayama, Y., 2017, The value of value chains for evaluating the socioeconomic benefits of Earth observations: GEOValue side event workshop, Washington, D.C., October 23-24, 2017, accessed July 28, 2017, at http://www.geovalue.org/wp-content/uploads/2018/04/ Kuwayama-presentation-2017-10-23.pptx.pdf.

Lave, L.B., 1963, The value of better weather information to the raisin industry: Econometrica, v. 31, nos. 1-2, p. 151164. [Also available at https://doi.org/10.2307/1910954.]

Longhorn, R.A., and Blakemore, M., 2007, Geographic information-Value, pricing, production, and consumption (1st ed.): Boca Raton, CRC Press, 248 p. [Also available at https://doi.org/10.1201/9781420005172.]

Miller, H.M., Richardson, Leslie, Koontz, S.R., Loomis, John, and Koontz, Lynne, 2013, Users, uses, and value of Landsat satellite imagery-Results from the 2012 survey of users: U.S. Geological Survey Open-File Report 2013-1269, 51 p. [Also available at http://dx.doi.org/10.3133/ofr20131269.]
Nordhaus, W.D., 1986. The value of information, in Krasnow, R., ed., Policy aspects of climate change: Proceedings of a Seminar, Washington, D.C., March 4, 1986.

Nordhaus, W.D., and Popp, D., 1997, What is the value of scientific knowledge? - An application to global warming using the PRICE model: The Energy Journal, v. 18, no. 1, p. 1-45. [Also available at https://www.jstor.org/ stable/41322716.]

Pielke, R.A., Jr., 1995, Usable information for policy-An appraisal of the U.S. Global Change Research Program: Policy Sciences, v. 28, no. 1, p. 39-77. [Also available at https://doi.org/10.1007/BF01000820.]

Porter, M.E., 1985, The competitive advantage - Creating and sustaining superior performance (1st ed.): New York, The Free Press.

Sawyer, G., 2017, A bottom-up approach to assessing the value of satellite EO data: GEOValue side event workshop, Washington, D.C., October 23-24, 2017, accessed July 28, 2017, at http://www.geovalue.org/wp-content/ uploads/2018/04/sawyer.pptx.pdf.

Sawyer, G., Dubost, A., and de Vries, M., 2016a, Copernicus Sentinels' products economic value-A case study of forest management in Sweden: European Association of Remote Sensing Companies, 51 p., accessed June 28, 2018, at http://earsc.org/file_download/307/case+report+-+forest + management + in + sweden + final + .pdf.

Sawyer, G., Dubost, A., and de Vries, M., 2016b, Copernicus Sentinels' products economic value-A case study of pipeline infrastructure monitoring in the Netherlands: European Association of Remote Sensing Companies, 50 p., accessed June 28, 2018, at http://earsc.org/file_download/341/ case+report+-- pipeline+infrastructure+in+Netherlands + final.pdf.

Schuster, R., Straub, C., and Miller, H., 2017, Communicating the value of Landsat imagery using case study narratives: GEOValue side event workshop, Washington, D.C., October 23-24, 2017, accessed July 28, 2017, at http://www.geovalue.org/wp-content/uploads/2018/04/ schuster.pptx.pdf.

Smart, A., 2017, Estimating the value of Earth observationsMethodologies: GEOValue side event workshop, Washington, D.C., October 23-24, 2017, accessed July 28, 2017 , at http://www.geovalue.org/wp-content/uploads/2018/04/ smart.pptx.pdf.

Sonka, S.T., Mjelde, J.W., Lamb, P.J., Hollinger, S.E., and Dixon, B.L., 1987, Valuing climate forecast information: Journal of Climate and Applied Meteorology, v. 26, no. 9 , p. 1080-1091. [Also available at https://doi.org/10.1175/1520-0450(1987)026<1080:VCFI> 2.0.CO;2.] 
U.S. Department of Commerce, 2014, Fostering innovation, creating jobs, driving better decisions - The value of government data: U.S. Department of Commerce, p. 15. [Also available at https://www.commerce.gov/sites/default/files/ migrated/reports/revisedfosteringinnovationcreatingjobs drivingbetterdecisions-thevalueofgovernmentdata.pdf.]

Veispak, A., 2017, Demonstrating the value and benefits of the Copernicus Programme: GEOValue side event workshop, Washington, D.C., October 23-24, 2017. 


\section{Glossary}

Copernicus The European Union's Earth Observation Programme, which provides satellite and in-situ data and information products.

counterfactual A scenario used in valuation studies that simulates the outcome of a policy or decision being analyzed, which can be used with baseline scenarios to demonstrate economic impacts of a policy or decision.

decision tree A framework for showing what data inputs are considered in a decision and what outcomes (and their respective probabilities) result.

Earth observation Spatial, temporal information, or both that represents a quantity, state, flux, or other quantitative measure of a physical, chemical, or biological process in the Earth system.

GRACE Gravity Recovery and Climate Experiment (GRACE) Satellites were a joint mission of National Aeronautics and Space Administration and the German Aerospace Center that detected anomalies of Earth's gravity field in an effort to track changes in the distribution of water on the planet.

Landsat A joint U.S. Geological Survey and National Aeronautics and Space Administration satellite program that has acquired imagery of Earth since 1972. It has applications in agriculture, geology, forestry, surveillance, and other fields.

revealed preference An economic valuation method that estimates prices by observation of consumer preferences.

stated preference Also referred to as contingent valuation, it is a method of valuing nonmarket resources by determining consumers' willingness to pay from survey responses.

value chain The connection of data sources, analyzed information, and decision points that enables the evaluation of how value-added information is integrated into the decisionmaking process. 


\section{Appendix 1. Attendee List}

Table 1.1. GEOValue side event attendee list, Washington, D.C., October 23-24, 2017.

[NOAA, National Oceanic and Atmospheric Administration; USGS, U.S. Geological Survey; SESYNC, The National Socio-Environmental Synthesis Center; IGES, Institute for Global Environmental Strategies; EC-JRC, European Commission's Joint Research Centre; NASA, National Aeronautics and Space Administration; PRSS, Performance, Risk and Social Science Office; CRCSI, Cooperative Research Centres for Spatial Information; RFF, Resources for the Future; EPA, U.S. Environmental Protection Agency; ERG, Eastern Research Group, Inc.; NSF, National Science Foundation; ESA, European Space Agency; GEO, Group on Earth Observations; EARSC, European Association for Remote Sensing Companies; DOI, U.S. Department of the Interior; NCEI, National Centers for Environmental Information; NOS, National Oceanic Service; NCCOS, National Centers for Coastal Ocean Science; EC, European Commission; DG GROW, Directorate-General Internal Market, Industry, Entrepreneurship and SMEs]

\begin{tabular}{|c|c|c|c|}
\hline Last name & First name & Organization & Contact information (email) \\
\hline Adkins & Jeff & NOAA & jeffery.adkins@noaa.gov \\
\hline Anand & Aanchal & World Bank & aanand1@worldbank.org \\
\hline Austin & Matt & NOAA & matthew.austin@noaa.gov \\
\hline Avery & Victoria & USGS & vavery@usgs.gov \\
\hline Boyd & Jim & SESYNC & boyd@rff.org \\
\hline Brown & Vankita & NOAA & vankita.brown@noaa.gov \\
\hline Carlis & $\mathrm{DaNa}$ & NOAA & dana.carlis@noaa.gov \\
\hline Colleton & Nancy & IGES & nancy_colleton@strategies.org \\
\hline Craglia & $\operatorname{Max}$ & $\mathrm{EC}-\mathrm{JRC}$ & massimo.craglia@jrc.ec.europa.eu \\
\hline Cummens & Patricia & EsriI & pcummens@esri.com \\
\hline Firth & John & Acclimatise & j.firth@acclimatise.uk.com \\
\hline Friedl & Lawrence & NASA & lfried1@nasa.gov \\
\hline Gallo & Jason & Science and Technology Policy Institute & jgallo@ida.org \\
\hline Geppi & Denna & NOAA & denna.geppi@noaa.gov \\
\hline Glynn & Pierre & USGS & pglynn@usgs.gov \\
\hline Graham & Jennifer & USGS & jlgraham@usgs.gov \\
\hline Kontoes & Haris & University of Athens & kontoes@noa.gr \\
\hline Kruse & Jamie & East Carolina University & krusej@ecu.edu \\
\hline Kuwayama & Yusuke & RFF & kuwayama@rff.org \\
\hline
\end{tabular}


Table 1.1. GEOValue side event attendee list, Washington, D.C., October 23-24, 2017.—Continued

[NOAA, National Oceanic and Atmospheric Administration; USGS, U.S. Geological Survey; SESYNC, The National Socio-Environmental Synthesis Center; IGES, Institute for Global Environmental Strategies; EC-JRC, European Commission's Joint Research Centre; NASA, National Aeronautics and Space Administration; PRSS, Performance, Risk and Social Science Office; CRCSI, Cooperative Research Centres for Spatial Information; RFF, Resources for the Future; EPA, U.S. Environmental Protection Agency; ERG, Eastern Research Group, Inc.; NSF, National Science Foundation; ESA, European Space Agency; GEO, Group on Earth Observations; EARSC, European Association for Remote Sensing Companies; DOI, U.S. Department of the Interior; NCEI, National Centers for Environmental Information; NOS, National Oceanic Service; NCCOS, National Centers for Coastal Ocean Science; EC, European Commission; DG GROW, Directorate-General Internal Market, Industry, Entrepreneurship and SMEs]

\begin{tabular}{|c|c|c|c|}
\hline Last name & First name & Organization & Contact information (email) \\
\hline Lawrence & Collin & USGS & cblawrence@usgs.gov \\
\hline Lipton & Doug & NOAA & douglas.lipton@noaa.gov \\
\hline Mason & Robert & USGS & rrmason@usgs.gov \\
\hline McGartland & $\mathrm{Al}$ & EPA & McGartland.al@Epa.gov \\
\hline Nadeau & Lou & ERG & Lou.Nadeau@erg.com \\
\hline O’Connor & Robert & NSF & roconnor@nsf.gov \\
\hline Ott & Michael & Intergovernmental Oceanographic Commission & m.ott@unesco.org \\
\hline Pearlman & Francoise & FourBridges & jsp@sprintmail.com \\
\hline Poudel & Rajendra & NOAA & rajendra.poudel@noaa.gov \\
\hline Pulwarty & Roger & NOAA & roger.pulwarty@noaa.gov \\
\hline Ramage & Steve & GEO Secretariat & sramage@geosec.org \\
\hline Sawyer & Geoff & EARSC & geoff.sawyer@earsc.org \\
\hline Schrab & Kevin & NOAA & kevin.schrab@noaa.gov \\
\hline Schuster & Rudy & USGS & rschuster@usgs.gov \\
\hline Shapiro & Carl & USGS & cshapiro@usgs.gov \\
\hline Simon & Benjamin & DOI & benjamin_simon@ios.doi.gov \\
\hline Thur & Steven & NOAA/NOS/NCCOS & Steven.Thur@noaa.gov \\
\hline Veispak & Andreas & EC-DG GROW & andreas.veispak@ec.europa.eu \\
\hline Williams & Jeff & NOAA & jeff.1.williams@noaa.gov \\
\hline
\end{tabular}




\title{
Appendix 2. Workshop Agenda
}

\author{
Day 1-Monday, October 23 \\ 9:00 a.m. Welcome address \\ Monica Grasso, National Oceanic and Atmospheric Administration (NOAA) \\ Carl Shapiro, U.S. Geological Survey (USGS) \\ Alessandra Tassa, European Space Agency (ESA) \\ Geoff Sawyer, European Association for Remote Sensing Companies (EARSC) \\ 9:20 a.m. Round table participant introductions \\ Participants provide 15 second self-introductions. \\ 9:30 a.m. Methodologies-Session 1 \\ Moderator: Steven Ramage, Group on Earth Observations (GEO) Secretariat \\ 1. Andreas Veispak, "Demonstrating the Value and Benefits of the Copernicus Programme" \\ 2. Alan Smart, "Methodologies for Evaluation" \\ 3. Stephane Hallegatte, "Simple Assessments of the Benefits from Early Warning Systems and Stron- \\ ger Hydro-Meteorological Systems" \\ 4. Andy Coote, "Value Chain and Cost-Benefit Analysis Applied to 3D Geo-Information" \\ 11:15 a.m. Break \\ 11:30 a.m. Methodologies-Session 2 \\ Moderator: Steven Ramage, GEO Secretariat \\ 1. Pat Cummens, "Esri Perspective" \\ 2. Rudy Schuster. "Communicating the Value of Landsat Imagery Using Case Study Narratives" \\ 3. Aanchal Anand, "The Economic Value of Geospatial Information: An Albania Case Study" \\ 4. Rich Bernknopf, “A Decision Framework for Quantifying the Economic Value of Information \\ of Earth Observation: Case of the NASA Gravity Recovery and Climate Experiment (GRACE) \\ Enhanced Drought Severity Index" \\ 5. Geoff Sawyer "A Bottom-Up Approach to Assessing the Value of Satellite EO Data" \\ 1:15 p.m. Lunch \\ 2:15 p.m. Introduction to value chains and processes panel—Session 3 \\ Moderator: Emily Pindilli, USGS \\ 1. Tim Stryker, USGS \\ 2. Jeff Adkins, NOAA \\ 3. Jamie Kruse, East Carolina University \\ 4. Yusuke Kuwayama, Resources for the Future \\ 3:45 p.m. Break \\ 4:00 p.m. Value chains forum: Session 4 \\ Moderator: Jay Pearlman, FourBridges \\ Open discussion on value chains, data/information requirements, and instructions for developing value \\ chains and identifying data requirements in topic areas. \\ 4:25 p.m. Wrap up of day 1 and plan for day 2 \\ 4:30 p.m. Adjourn
}




\section{Day 2-Tuesday, October 24}

9:00 a.m. Welcome address, recap of day 1, plan for day 2

9:30 a.m. Value chain development working groups (group members predetermined) for monitoring and forecasting:

Group 1: Effect of increasing temperatures on human health

Group 2: Floodings - Mitigating, managing, and avoiding impacts to safety and property damage

Group 3: Harmful algal blooms-Effects on human health, recreation, and tourism

Group 4: Energy and mineral supply-Mitigating, managing, and avoiding impacts of shortfalls on the economy

Group 5: Effects of natural hazards on transportation systems-Effects on mobility, safety, and the economy

10:30 a.m. Break

11:00 a.m. Identifying data requirements work groups (same groups)

12:00 p.m. $\quad$ Lunch

1:00 p.m. Group sharing activity (describe results of working session)

2:15 p.m. Break

2:30 p.m. Guidance document scoping

Moderator: Monica Grasso, NOAA

Participants will be engaged in discussion of a guidance document that uses the methodologies, value chains, and information needs determined during the workshop to provide recommendations for ongoing socioeconomic data monitoring and next steps.

3:30 p.m. Wrap up, next steps, and commitments

4:00 p.m. Adjourn 
For more information about this publication, contact: Science and Decisions Center

\section{U.S. Geological Survey}

913 National Center

12201 Sunrise Valley Drive

Reston, VA 20192

gs_emeh_sdc@usgs.gov

https://www2.usgs.gov/sdc/

Publishing support provided by the

Reston and Rolla Publishing Service Centers 



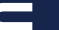

B

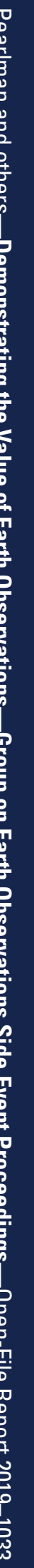

